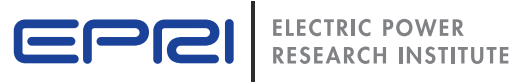

Assessment and Mapping of the Riverine Hydrokinetic Resource in the Continental United States 



\section{Assessment and Mapping of the Riverine Hydrokinetic Energy Resource in the Continental United States}

EPRI Project Manager P. Jacobson

\section{Erel| \begin{tabular}{|l|l} 
ELETTIC POWER \\
RESEARCH INSTIUUTE
\end{tabular}} 3420 Hillview Avenue Palo Alto, CA 94304-1338

\section{0}

Final Report, December 2012 


\section{DISCLAIMER OF WARRANTIES AND LIMITATION OF LIABILITIES}

THIS DOCUMENT WAS PREPARED BY THE ORGANIZATION(S) NAMED BELOW AS AN ACCOUNT OF WORK SPONSORED OR COSPONSORED BY THE ELECTRIC POWER RESEARCH INSTITUTE, INC. (EPRI). NEITHER EPRI, ANY MEMBER OF EPRI, ANY COSPONSOR, THE ORGANIZATION(S) BELOW, NOR ANY PERSON ACTING ON BEHALF OF ANY OF THEM:

(A) MAKES ANY WARRANTY OR REPRESENTATION WHATSOEVER, EXPRESS OR IMPLIED, (I) WITH RESPECT TO THE USE OF ANY INFORMATION, APPARATUS, METHOD, PROCESS, OR SIMILAR ITEM DISCLOSED IN THIS DOCUMENT, INCLUDING MERCHANTABILITY AND FITNESS FOR A PARTICULAR PURPOSE, OR (II) THAT SUCH USE DOES NOT INFRINGE ON OR INTERFERE WITH PRIVATELY OWNED RIGHTS, INCLUDING ANY PARTY'S INTELLECTUAL PROPERTY, OR (III) THAT THIS DOCUMENT IS SUITABLE TO ANY PARTICULAR USER'S CIRCUMSTANCE; OR

(B) ASSUMES RESPONSIBILITY FOR ANY DAMAGES OR OTHER LIABILITY WHATSOEVER (INCLUDING ANY CONSEQUENTIAL DAMAGES, EVEN IF EPRI OR ANY EPRI REPRESENTATIVE HAS BEEN ADVISED OF THE POSSIBILITY OF SUCH DAMAGES) RESULTING FROM YOUR SELECTION OR USE OF THIS DOCUMENT OR ANY INFORMATION, APPARATUS, METHOD, PROCESS, OR SIMILAR ITEM DISCLOSED IN THIS DOCUMENT.

REFERENCE HEREIN TO ANY SPECIFIC COMMERCIAL PRODUCT, PROCESS, OR SERVICE BY ITS TRADE NAME, TRADEMARK, MANUFACTURER, OR OTHERWISE, DOES NOT NECESSARILY CONSTITUTE OR IMPLY ITS ENDORSEMENT, RECOMMENDATION, OR FAVORING BY EPRI.

THIS MATERIAL IS BASED ON WORK SUPPORTED BY THE DEPARTMENT OF ENERGY UNDER AWARD NUMBER DE-EEO002662.

THIS REPORT WAS PREPARED AS AN ACCOUNT OF WORK SPONSORED BY AN AGENCY OF THE UNITED STATES GOVERNMENT. NEITHER THE UNITED STATES GOVERNMENT NOR ANY AGENCY THEREOF, NOR ANY OF THEIR EMPLOYEES, MAKES ANY WARRANTY, EXPRESS OR IMPLIED, OR ASSUMES ANY LEGAL LIABILITY OR RESPONSIBILITY FOR THE ACCURACY, COMPLETENESS, OR USEFULNESS OF ANY INFORMATION, APPARATUS, PRODUCT, OR PROCESS DISCLOSED, OR REPRESENTS THAT ITS USE WOULD NOT INFRINGE PRIVATELY OWNED RIGHTS. REFERENCE HEREIN TO ANY SPECIFIC COMMERCIAL PRODUCT, PROCESS, OR SERVICE BY TRADE NAME, TRADEMARK, MANUFACTURER, OR OTHERWISE DOES NOT NECESSARILY CONSTITUTE OR IMPLY ITS ENDORSEMENT, RECOMMENDATION, OR FAVORING BY THE UNITED STATES GOVERNMENT OR ANY AGENCY THEREOF. THE VIEWS AND OPINIONS OF AUTHORS EXPRESSED HEREIN DO NOT NECESSARILY STATE OR REFLECT THOSE OF THE UNITED STATES GOVERNMENT OR ANY AGENCY THEREOF.

THE FOLLOWING ORGANIZATIONS, UNDER CONTRACT TO EPRI, PREPARED THIS REPORT:

\section{University of Alaska Anchorage \\ University of Alaska Fairbanks \\ National Renewable Energy Laboratory}

\section{NOTE}

For further information about EPRI, call the EPRI Customer Assistance Center at 800.313.3774 or e-mail askepri@epri.com.

Electric Power Research Institute, EPRI, and TOGETHER...SHAPING THE FUTURE OF ELECTRICITY are registered service marks of the Electric Power Research Institute, Inc.

Copyright $\odot 2012$ Electric Power Research Institute, Inc. All rights reserved. 


\section{Acknowledgments}

This publication is a corporate document that should be cited in the literature in the following manner:

Assessment and Mapping of the Riverine Hydrokinetic Energy

Resource in the Continental United States.

EPRI, Palo Alto, CA: 2012.

1026880.
The following organizations, under contract to the Electric Power Research Institute (EPRI), contributed to this report:

University of Alaska-Anchorage

3211 Providence Drive

Anchorage, AK 99508

Principal Investigator

T. Ravens

University of Alaska-Fairbanks

3352 College Road

Fairbanks, AK 99775

Principal Investigator

K. Cunningham

National Renewable Energy Laboratory

1617 Cole Blvd.

Golden, CO 80401

Principal Investigator

G. Scott

This report describes research sponsored by EPRI.

EPRI would like to thank participants in the expert and user group workshops who contributed their expertise during the course of this project, including: Donald Atwood, University of Alaska Fairbanks; Neil McMahon, Alaska Energy Authority; Kernell Reiss, U.S. Geological Survey; Edward Lovelace, Free Flow Power; David Meyers, U.S. Geological Survey; Wayne Jenkinson, National 
Research Council Canada; Mollie Gardner, Verdant Power; Clayton Bear, New Energy Corporation; Mary Ann Adonizio, Verdant Power; Sean Anderton, Ocean Renewable Power Company; Roger Bedard, EPRI (retired); Howard Hanson, Florida Atlantic University; Tim Hogan, Alden; Gary Johnson, Pacific Northwest National Laboratory; Tim Konnert, Federal Energy Regulatory Commission; John Miller, University of Massachusetts-Dartmouth; Brian Polagye, University of Washington; Mirko Previsic, Re Vision Consulting; Kamau Sadiki, U.S. Army Corps of Engineers; Larry Weber, University of Iowa.

EPRI would also like to thank Hoyt Battey, Caitlin Frame, and Brooke White of the U.S. Department of Energy for their interest in and contributions to this project, and for initiating a review of this project by the National Research Council Committee on Marine and Hydrokinetic Energy Technology Assessment. Engagement by the DOE and the NRC has enhanced the rigor and utility of the project. 


\section{Product Description}

This report describes the methodology and results of the most rigorous assessment to date of the riverine hydrokinetic energy resource in the contiguous 48 states and Alaska, excluding tidal waters. The assessment provides estimates of the gross, naturally available resource, termed the theoretical resource, as well as estimates, termed the technically recoverable resource, that account for selected technological factors affecting capture and conversion of the theoretical resource. The technically recoverable resource does not account for all technical constraints on energy capture and conversion.

\section{Background}

The U.S. Department of Energy (DOE) funded the Electric Power Research Institute and its collaborative partners, University of Alaska - Anchorage, University of Alaska - Fairbanks, and the National Renewable Energy Laboratory, to provide an assessment of the riverine hydrokinetic resource in the continental United States.

\section{Objectives}

The goal of this project was to estimate the riverine hydrokinetic resource in the continental United States.

\section{Approach}

The project team derived an assessment of the hydrokinetic resource in the 48 contiguous states from spatially explicit data contained in NHDPlus, a geographic information system (GIS)-based database containing river segment-specific information on discharge characteristics and channel slope. The team estimated the segmentspecific theoretical resource from these data using the standard hydrological engineering equation that relates theoretical hydraulic power $\left(\mathrm{P}_{\text {th }}\right.$, Watts $)$ to discharge $\left(\mathrm{Q}_{2} \mathrm{~m}^{3} \mathrm{~s}^{-1}\right)$ and hydraulic head or change in elevation $(\Delta H, \mathrm{~m})$ over the length of the segment, where $\gamma$ is the specific weight of water $\left(9800 \mathrm{~N} \mathrm{~m}^{-3}\right)$ :

$$
P_{t h}=\gamma Q \Delta H
$$


For Alaska, which is not encompassed by NHDPlus, the team manually obtained hydraulic head and discharge data from Idaho National Laboratory's Virtual Hydropower Prospector, Google Earth, and U.S. Geological Survey gages. The team estimated the technically recoverable resource by applying a recovery factor to the segment-specific theoretical resource estimates. This analysis, which included 32 scenarios, led to an empirical function relating recovery factor to slope and discharge. For Alaska, where data on river slope was not readily available, the recovery factor was estimated based on the flow rate alone.

\section{Results}

Segment-specific theoretical resource, aggregated by major hydrologic region in the contiguous, lower 48 states, totaled 1,146 $\mathrm{TWh} / \mathrm{yr}$. The aggregate estimate of the Alaska theoretical resource is $235 \mathrm{TWh} / \mathrm{yr}$, yielding a total theoretical resource estimate of 1,381 TWh/yr for the continental United States. The technically recoverable resource estimate for the continental United States is 120 $\mathrm{TWh} / \mathrm{yr}$.

Results of this study can be geo-spatially visualized, queried, and downloaded from the National Renewable Energy Laboratory's website at: http://maps.nrel.gov/river atlas. Currently, results are only available for the 48 contiguous states. Alaska will be added in the future.

\section{Applications, Values, and Use}

While the calculation of the technically recoverable hydrokinetic resource takes into account some important constraints, a fuller accounting of additional practical constraints on turbine deployment would further reduce the portion of the theoretical resource that is estimated to be recoverable. The practically recoverable resource remains an unknown - and perhaps small -- portion of the technically recoverable resource. Additional data, assumptions, and highly detailed analysis are required to reliably estimate the practically recoverable hydrokinetic resource.

\section{Keywords}

Hydrokinetic resources

Hydropower

Renewable resources 


\section{Executive} Summary
The U.S. Department of Energy (DOE) funded the Electric Power Research Institute and its collaborative partners, University of Alaska - Anchorage, University of Alaska - Fairbanks, and the National Renewable Energy Laboratory, to provide an assessment of the riverine hydrokinetic resource in the continental United States. The assessment benefited from input obtained during two workshops attended by individuals with relevant expertise and from a National Research Council panel commissioned by DOE to provide guidance to this and other concurrent, DOE-funded assessments of waterbased renewable energy. These sources of expertise provided valuable advice regarding data sources and assessment methodology.

The assessment of the hydrokinetic resource in the 48 contiguous states is derived from spatially-explicit data contained in NHDPlus a GIS-based database containing river segment-specific information on discharge characteristics and channel slope. 71,398 river segments with mean annual flow greater than 1,000 cubic feet per second (cfs) mean discharge were included in the assessment. Segments with discharge less than 1,000 cfs were dropped from the assessment, as were river segments with hydroelectric dams. The results for the theoretical and technical resource in the 48 contiguous states were found to be relatively insensitive to the cutoff chosen. Raising the cutoff to 1,500 cfs had no effect on estimate of the technically recoverable resource, and the theoretical resource was reduced by $5.3 \%$.

The segment-specific theoretical resource was estimated from these data using the standard hydrological engineering equation that relates theoretical hydraulic power $\left(\mathrm{P}_{\mathrm{th}}\right.$, Watts) to discharge $\left(\mathrm{Q}_{2} \mathrm{~m}^{3} \mathrm{~s}^{-1}\right)$ and hydraulic head or change in elevation $(\Delta H, \mathrm{~m})$ over the length of the segment, where $\gamma$ is the specific weight of water $\left(9800 \mathrm{~N} \mathrm{~m}^{-3}\right)$ :

$$
P_{t h}=\gamma Q \Delta H
$$

For Alaska, which is not encompassed by NPDPlus, hydraulic head and discharge data were manually obtained from Idaho National Laboratory's Virtual Hydropower Prospector, Google Earth, and U.S. Geological Survey gages. Data were manually obtained for the eleven largest rivers with average flow rates greater than $10,000 \mathrm{cfs}$ and the resulting estimate of the theoretical resource was expanded to 
include rivers with discharge between $1,000 \mathrm{cfs}$ and 10,000 cfs based upon the contribution of rivers in the latter flow class to the total estimate in the contiguous 48 states.

Segment-specific theoretical resource was aggregated by major hydrologic region in the contiguous, lower 48 states (Table ES-1) and totaled 1,146 TWh/yr. The aggregate estimate of the Alaska theoretical resource is $235 \mathrm{TWh} / \mathrm{yr}$, yielding a total theoretical resource estimate of $1,381 \mathrm{TWh} / \mathrm{yr}$ for the continental US.

The technically recoverable resource in the contiguous 48 states was estimated by applying a recovery factor to the segment-specific theoretical resource estimates. The recovery factor scales the theoretical resource for a given segment to take into account assumptions such as minimum required water velocity and depth during low flow conditions, maximum device packing density, device efficiency, and flow statistics (e.g., the 5 percentile flow relative to the average flow rate). The recovery factor also takes account of "back effects" - feedback effects of turbine presence on hydraulic head and velocity. The recovery factor was determined over a range of flow rates and slopes using the hydraulic model, HEC-RAS. In the hydraulic modeling, presence of turbines was accounted for by adjusting the Manning coefficient. This analysis, which included 32 scenarios, led to an empirical function relating recovery factor to slope and discharge. Sixty-nine percent of NHDPlus segments included in the theoretical resource estimate for the contiguous 48 states had an estimated recovery factor of zero. For Alaska, data on river slope was not readily available; hence, the recovery factor was estimated based on the flow rate alone. Segment-specific estimates of the theoretical resource were multiplied by the corresponding recovery factor to estimate the technically recoverable resource. The resulting technically recoverable resource estimate for the continental United States is $120 \mathrm{TWh} / \mathrm{yr}$ (Table 1). 
Table 1

Theoretical and technically recoverable hydrokinetic energy estimates for the continental United States.

\begin{tabular}{|c|c|c|}
\hline $\begin{array}{l}\text { Hydrologic } \\
\text { Region }\end{array}$ & $\begin{array}{c}\text { Theoretical Power } \\
\text { (Annual Energy } \\
\text {,TWh/yr) }\end{array}$ & $\begin{array}{c}\text { Technically } \\
\text { Recoverable } \\
\text { Power (Annual } \\
\text { Energy, TWh/yr) }\end{array}$ \\
\hline New England & 14.4 & 0.2 \\
\hline Mid Atlantic & 33.5 & 1.0 \\
\hline South Atlantic Gulf & 38.5 & 1.2 \\
\hline Great Lakes & 6.2 & 0.01 \\
\hline Ohio & 79.2 & 6.9 \\
\hline Tennessee & 20.4 & 1.0 \\
\hline Sauris Red-Rainy & 1.8 & 0.03 \\
\hline Upper Mississippi & 47.0 & 5.1 \\
\hline Lower Mississippi & 208.8 & 57.4 \\
\hline Texas Gulf & 8.9 & 0.05 \\
\hline Arkansas Red & 45.1 & 1.3 \\
\hline Lower Missouri & 79.8 & 5.6 \\
\hline Upper Missouri & 74.3 & 2.8 \\
\hline Rio Grande & 29.5 & 0.3 \\
\hline Lower Colorado & 57.6 & 3.9 \\
\hline Upper Colorado & 46.9 & 1.1 \\
\hline Great Basin & 6.9 & 0 \\
\hline California & 50.9 & 0.7 \\
\hline Pacific Northwest & 296.7 & 11.0 \\
\hline Alaska & 235 & 20.5 \\
\hline Total & 1,381 & 119.9 \\
\hline
\end{tabular}

The Lower Mississippi region contributes nearly half (47.9\%) of the total resource estimate. The major rivers of Alaska constitute $17.1 \%$ of the total for the continental U.S. The next largest contributor is the Pacific Northwest region, which contributes $9.2 \%$, followed by the Ohio region (5.7\%). Collectively these four regions encompass $80 \%$ of the technically recoverable hydrokinetic resource in the continental U.S. 
While the calculation of the technically recoverable hydrokinetic resource takes into account some important constraints, a fuller accounting of additional practical constraints on turbine deployment would further reduce the portion of the theoretical resource that is estimated to be recoverable. The practically recoverable resource remains an unknown - and perhaps small -- portion of the technically recoverable resource. Additional data, assumptions, and highly detailed analysis are required to reliably estimate the practically recoverable hydrokinetic resource.

Results of this study can be geo-spatially visualized, queried, and downloaded from the National Renewable Energy Laboratory's website at: http://maps.nrel.gov/river atlas. Currently, results are only available for the 48 contiguous states. Alaska will be added in the future. 
Section 1: Introduction and Background ................... 1-1

Definition of the Theoretical and Technical In-Stream

Hydrokinetic Resource

Section 2: Methodology for Estimating the Theoretically Available In-stream Hydrokinetic Resource

Contiguous 48 States

Preparing the Data

Alaska

Section 3: Results for Theoretically Available Hydrokinetic Resource

Section 4: Methodology for Estimating the Technically Recoverable In-Stream Hydrokinetic Resource

Section 5: Results for the Technically Recoverable Hydrokinetic Resource ...............................5-1

Section 6: Uncertainty of the estimates of the Theoretical and Technically Recoverable Hydrokinetic Resource...........6-1

Section 7: GIS Display ...........................................7-1

Data Processing .................................................................

Tool Functionality and Capabilities...................................

Application Analysis..................................................

Intended Audience ...................................................

Section 8: Conclusions ................................................8-1

Appendix A: Validation ......................................... A-1 


\section{Appendix B: Hydraulic Impacts of Hydrokinetic}

Devices

Abstract

Introduction

Analysis

Representation of hydrokinetic devices with an

enhanced bottom roughness

Channel energy losses due to presence of

hydrokinetic devices

Determination of water depth with devices present

Determination of the effective Manning's roughness coefficient and velocity with devices present

Example calculation of the hydraulic impact of a uniform distribution of hydrokinetic devices.

Hydraulic impacts of HK devices associated with deployments in spatially limited areas

Notation

\section{Appendix C: Theoretical and Technically Recoverable Riverine Hydrokinetic Power in Alaska} C-1

\section{Appendix D:}


Figure 2-1 Flowlines of various lengths and downstream directions near St Louis.

Figure 2-2 Screenshot of NHDPlus data showing flowline identifier (FID), Geographic Names Information System ID (GNIS_ID), river name (GNIS_NAME), length (LENGTHKM, km), computed mean annual flow (MAFLOWU, cfs), and average slope (SLOPE, unitless rise over run).

Figure 2-3 Riverine resources and hydrographic regions for which the theoretical power is calculated.

Figure 2-4 Ratio of the theoretical power from flows above $10,000 \mathrm{cfs}$ to power from flows above 1,000 $\left(R_{10,000 / 1,000}\right)$ for the 19 hydrologic regions of the contiguous US as a function of maximum annual discharge rate in that region.

Figure 4-1 Display of calculated velocity and depth in idealized "V-shaped" channel for $Q_{5}=1800 \mathrm{~m}^{3} / \mathrm{s}$ and river slope $=0.0001$. The red dots indicate the left and right bank areas.

Figure 4-2 Two views of a plot of the Recovery Factor scenario results (data points) listed in Table 4.3 and fitted Recovery Factor function (surface plot).

Figure 4-3 Plot showing the relationship between Recovery Factor and discharge based on data in Table 4.3.

Figure 6-1 Comparison of NHDPlus-estimated discharge and USGS gage measured discharge at selected locations in each of the hydrologic regions of the US. 
Figure B-1 Plot of normalized depth $\left(h_{1} / h\right)$, normalized velocity $(V / V)$, normalized effective Manning roughness $(n, / n)$, power density $\left(P D, k W m^{-2}\right)$, extracted power in a 500-m long channel section (P, kW ), and blockage ratio as a function of density of hydrokinetic devices (number of devices per $10 \mathrm{D} \mathrm{m}$ length).

Figure B-2 Cartoon illustrating the spatially limited deployment of hydrokinetic devices.

Figure B-3 Hydraulic impact of a spatially-limited deployment of hydrokinetic devices including (a) velocity and water depth within $75 \mathrm{~km}$ of the hydrokinetic devices; (b) Velocity and water depth within $0.5 \mathrm{~km}$ of the devices; and (c) normalized velocity and normalized depth proximal to the devices. 
Table 2-1 Analysis of discharge data from the Prospector and from USGS gages for the Alaska portion of the study.

Table 2-2 Analysis of elevation change data from Google Earth and from the Prospector for the Alaska portion of the study.

Table 3-1 Theoretical power (annual energy) presented in units of terawatt hours per year aggregated by hydrologic regions that are depicted in Figure 3.1 and Alaska.

Table 4-1 Discharge statistics assumed for recovery factor calculations based on measured discharge statistics from Vicksburg on the Mississippi River. The normalized discharge is the discharge relative to the annual average $\left(17,000 \mathrm{~m}^{3} / \mathrm{s}\right)$.

Table 4-2 Variation of Recovery Factor with discharge for a $V$-shaped channel with an annual average flow rate of $10,000 \mathrm{~m}^{3} / \mathrm{s}$ and a slope of 0.0005 .

Table 4-3 Discharge - river slope scenarios and recovery factor calculation results. $\mathrm{ND}=$ no data

Table 5-1 Technically recoverable hydrokinetic resource for the continental United States, by hydrologic region depicted in Figure 3.1 and for Alaska.

Table 6-1 Uncertainty analysis of river elevation change between headwaters and mouth

Table 6-2 Sensitivity of Recovery Factor calculation

Table A-1 Top Rivers by Power Production

Table B-1 Channel, flow, and turbine properties assumed in example calculation.

Table B-2 Channel, flow and turbine properties assumed. 
Table C-1 Theoretical in-stream hydrokinetic power in segments of the major Alaska rivers in which the annual average flow rate exceeds $10,000 \mathrm{cfs}\left(283 \mathrm{~m}^{3} / \mathrm{s}\right)$.

Table C-2 Technically recoverable hydrokinetic resource (TWh/yr) in portions of selected Alaska rivers with average discharge greater than 10,000 cfs. C-6 


\section{Section 1: Introduction and Background}

This report describes the methodology and results of the most rigorous assessment to date of the riverine hydrokinetic energy resource in the contiguous 48 states and Alaska, excluding tidal waters. The assessment provides estimates of the gross, naturally available resource, termed the theoretical resource, as well as estimates, termed the technically recoverable resource, that account for selected technological factors affecting capture and conversion of the theoretical resource. The technically recoverable resource, as defined in this study does not account for all technical constraints on energy capture and conversion.

The practical resource - the resource that could be recovered considering additional factors such as existing uses, environmentally sensitive and other exclusion areas, economic constraints, and access to load or transmission - is an unknown fraction of the technically recoverable resource. This report does not provide an assessment of the practical resource; nor does it provide the information needed to site projects. Far more detailed study is required to estimate the practical resource and to select candidate sites for hydrokinetic project development.

This report is intended to provide policymakers, project developers, hydrokinetic energy device developers, investors, universities, non-governmental organizations, environmental groups, the U.S. Department of Energy (DOE), the military, and the U.S. Army Corps of Engineers and the U.S. Geological Survey an assessment of the general magnitude and geographic distribution of the riverine hydrokinetic resource across the continental United States.

The DOE previously commissioned a study of the U.S. hydrokinetic energy resource (Miller et al. 1986). That study derived estimates of hydrokinetic power for selected river segments in 12 of 16 hydrologic regions of the U.S. with mean discharge of at least 4,000 cubic feet per second (cfs) and velocity greater than 4.3 feet per second (fps). Within each of the regions in which these criteria were met, the rivers with the greatest potential were selected for assessment. This procedure provided estimates of recoverable power in the rivers with the greatest potential in each of the regions meeting the minimum criteria; however, the criteria for inclusion in the study differed among regions. Recoverable power was estimated assuming turbine deployment in $25 \%$ of the estimated width and $25 \%$ of river segment lengths meeting the minimum discharge criteria, turbine diameter equal to $80 \%$ of the mean depth, turbine spacing of half a turbine diameter space between turbines in each row and 5 turbine diameters spacing between rows, and system efficiency of 40\%. Miller et al. (1986) did not include 
the feedback effects of turbine deployment on water velocity. The foregoing methodology applied to the selected river segments yielded an aggregate power estimate slightly greater than $12,500 \mathrm{MW}$ average annual power (110 TWh/yr). There are no other broad-scale riverine hydrokinetic resource assessments for the United States. Canada is currently conducting an assessment of its riverine hydrokinetic resource (NRC-CHC 2010).

The present assessment improves upon the estimate of Miller et al. (1986) in a number of ways. It includes the potential energy associated with hydraulic head as well as the back effects of turbine deployment. It also applies a consistent criterion for inclusion across the contiguous 48 states, and explicitly assesses a larger number of rivers in Alaska. The threshold for inclusion in this assessment is 1,000 cfs mean discharge, making the present assessment more comprehensive in its scope. This assessment, however, makes different assumptions regarding turbine deployment, leading to a flow threshold for hydrokinetic energy recovery of 7,000 cfs mean discharge.

The choice of databases selected for this study, as well as the underlying methodology and analytical assumptions, benefited from advice acquired in two expert workshops. The project also benefited from review and input by a committee of the National Research Council that was commissioned by DOE to review this resource assessment and the related, DOE-funded assessments of other water-based resource types.

\section{Definition of the Theoretical and Technical In-Stream Hydrokinetic Resource}

The in-stream (non-tidal) hydrokinetic power theoretically available in a given river segment $\left(P_{t b}\right.$, Watts $)$ is defined:

$$
P_{t h}=\gamma Q \Delta H
$$

where $\gamma$ is the specific weight of water $\left(\sim 9800 \mathrm{~N} \mathrm{~m}^{-3}\right)$,

$Q$ is the flow rate $\left(\mathrm{m}^{3} / \mathrm{s}\right)$, and

$\Delta H(\mathrm{~m})$ is the change in hydraulic head between the beginning and end of the river segment.

The in-stream hydrokinetic power technically recoverable in a given river segment $\left(P_{\text {tech }}\right.$, Watts) is the portion of the theoretically available power that can be recovered given selected technical constraints and assumptions, including:

a) water depth at the 5-percentile flow (the flow exceeded $95 \%$ of the time) greater than or equal to $2.0 \mathrm{~m}$,

b) depth-averaged velocity of the 5-percentile flow greater than or equal to 0.5 $\mathrm{m} / \mathrm{s}$, 
c) "rule-of-thumb" device spacing, and

d) $30 \%$ "water to wire" device efficiency including efficiencies of: rotor, gearbox, generator, frequency converter, and step-up transformer (EPRI 2008).

The technically available hydrokinetic power estimates incorporate "back effects" - feedback effects of energy extraction on river depth and velocity. Section 4 provides a detailed description of the methodology used to estimate the technically recoverable resource. 



\section{Section 2: Methodology for Estimating the Theoretically Available In- stream Hydrokinetic Resource}

This section describes the methodology for estimating the theoretically available, non-tidal, riverine hydrokinetic resource. Consultation with an expert panel convened in April 2010 to support this assessment identified NHDPlus as the most suitable hydrography dataset for assessment of the hydrokinetic resource. Currently, the NHDPlus database covers the 48 contiguous states, but does not encompass Alaska; consequently, a different data source and methodology are required for the State of Alaska. NHDPlus is described briefly below.

Additional information and documentation is available at: www.horizonsystems.com/nhdplus/.

\section{Contiguous 48 States}

Mapping data exists to estimate the available power from the rivers in the contiguous United States. This mapping data is in the form of a geographic information system (GIS) and is part of the US National Map developed by the US Geological Survey (USGS). The GIS layer of the US National Map with river data is the National Hydrography Dataset (NHD). In addition to rivers, NHD includes other hydrographic features such as shorelines, lakes and ponds, as well as canals and aqueducts.

The Environmental Protection Agency (EPA) collaborated with the USGS to enhance NHD to support EPA's water quality modeling activities. The enhanced GIS database, called NHDPlus, represents hydrologic networks as networks of "flowlines". Individual flowlines range in length from $1 \mathrm{~m}$ to $41 \mathrm{~km}$, and each has an assigned average velocity, discharge, and slope. These flowlines and associated data constitute the basic geo-spatial units of analysis for the portion of this study encompassing the 48 contiguous states. We use the term segments to refer to these geo-spatial units of analysis.

Figure 2.1 below shows NHDPlus flowlines for the Mississippi, Missouri, and Illinois rivers at St Louis, Missouri overlaid on a map of the area. The arrowhead at the bottom of each flowline indicates the direction of flow. This example illustrates discrepancies between the flowlines in NHDPlus and river courses depicted in a more recent map. 


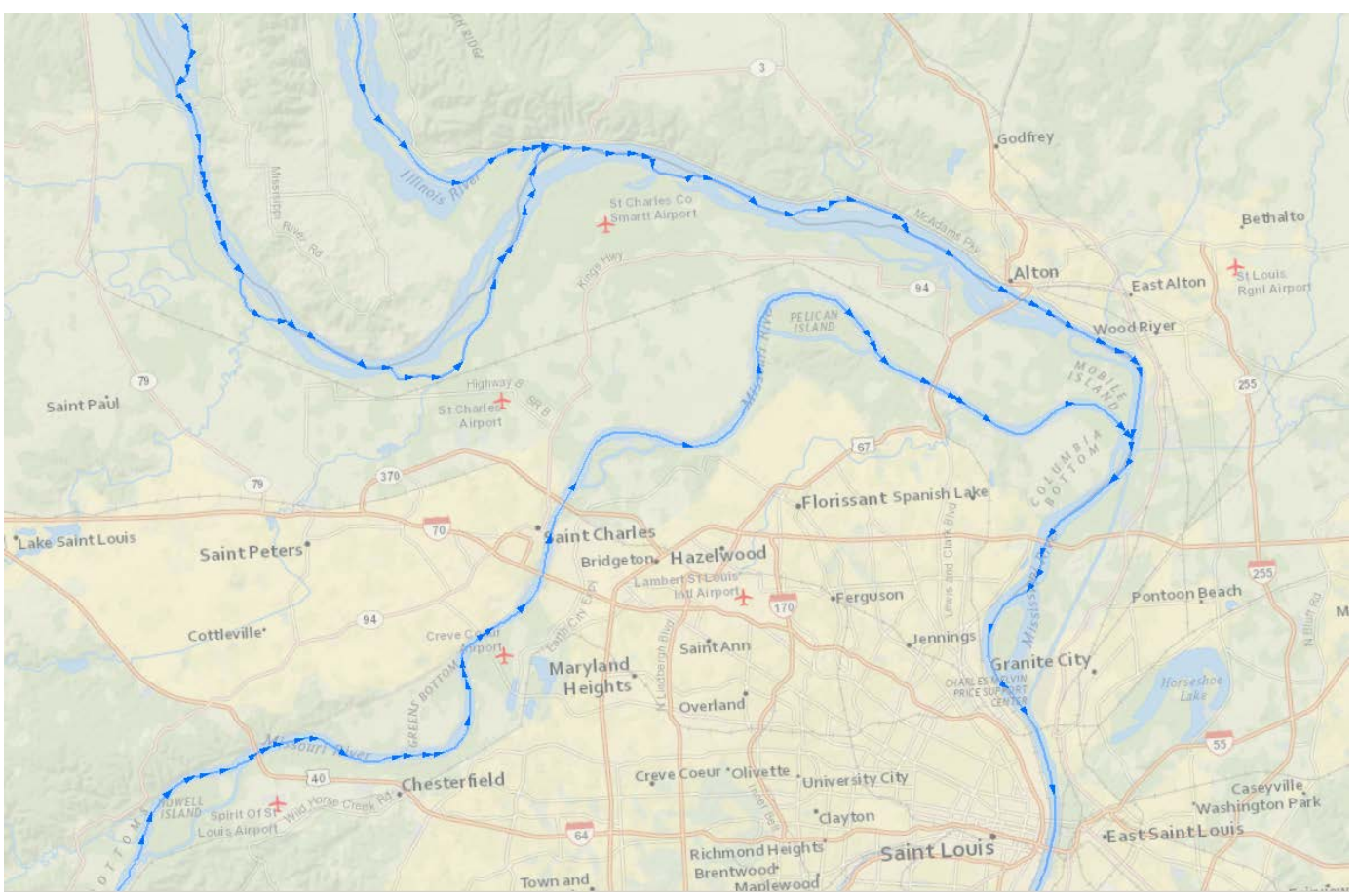

Figure 2-1

Flowlines of various lengths and downstream directions near St Louis.

Theoretical power is estimated according to Equation 1.1, using the segmentspecific average water discharge (Q) provided by NHDPlus in units of cubic feet per second (cfs). Hydraulic head $(\Delta \mathrm{H})$ is calculated from segment length and slope. Figure 2.2 shows GIS data for a number of NHDPlus flowlines (segments). NHDPlus provides two estimates of annual discharge but only one (MAFLOWU) is available in all of the river segments. Hence, the " MAFLOWU" estimate of discharge is used in this study. 


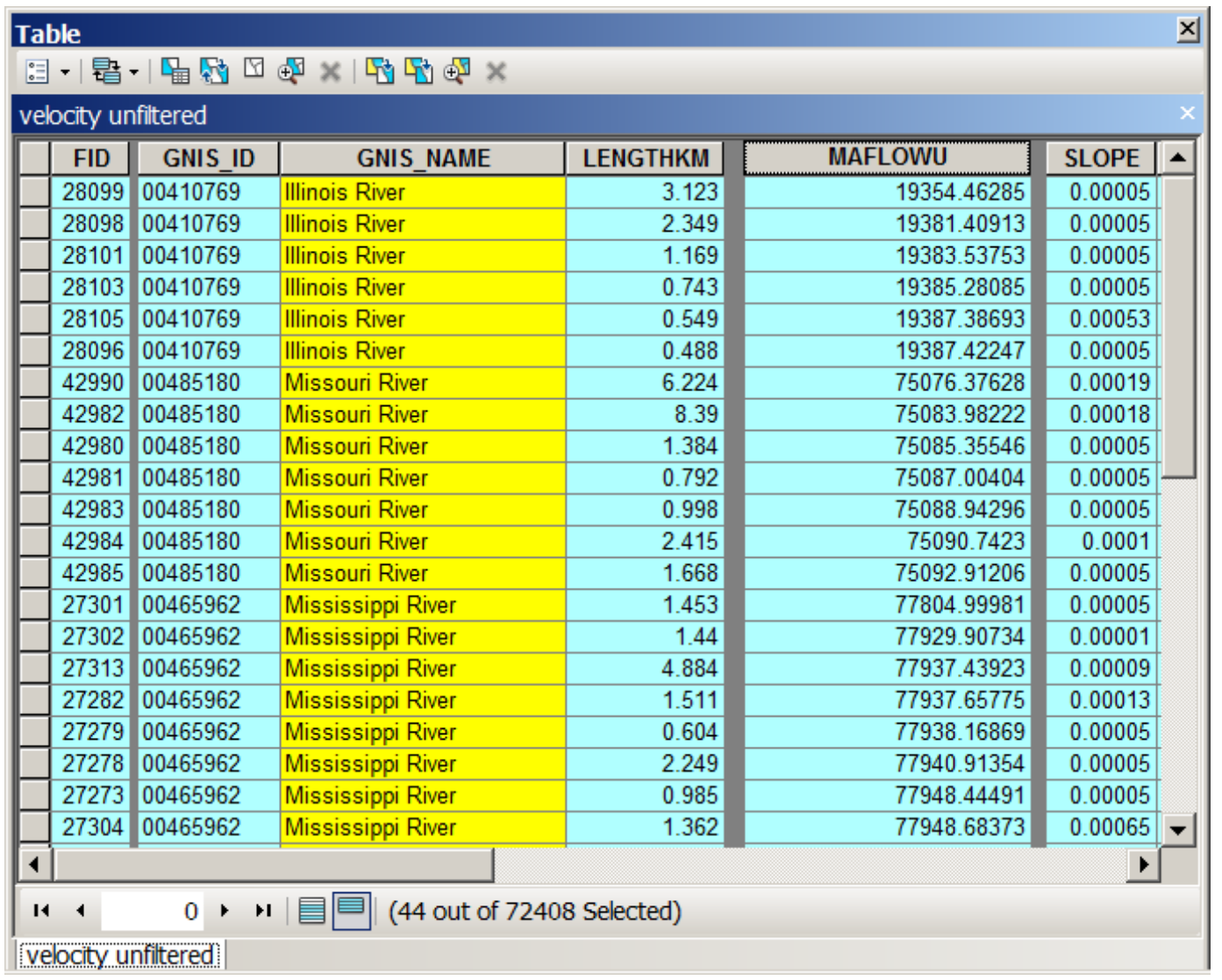

\section{Figure 2-2}

Screenshot of NHDPlus data showing flowline identifier (FID), Geographic Names Information System ID (GNIS_ID), river name (GNIS_NAME), length (LENGTHKM, $\mathrm{km})$, computed mean annual flow (MAFLOWU, cfs), and average slope (SLOPE, unitless rise over run).

\section{Preparing the Data}

This assessment is limited to the riverine hydrokinetic resource; thus, NHDPlus records pertaining to lakes, reservoirs, ponds, etc. are excluded from the analysis. Smaller rivers and stream segments with discharge of less than 1,000 cubic feet per second (cfs) are also excluded. The minimum flow criterion was selected in consultation with the expert panel convened on April 27, 2011.

Segments containing dams with hydroelectric plants were also excluded from analysis. Existing hydroelectric generating facilities for the analysis were determined using licensed data from the Homeland Security Infrastructure Program (HSIP). Hydroelectric plants were spatially referenced by feature intersection with the NHDPlus data using a 0.25 mile buffer around the HSIP hydroelectric plants. River segments that were intersected within the buffer were analyzed by their delta-H attribute (difference in elevation between segment endpoints) and ranked in order from largest to smallest. The river segments with the largest delta-H values from each hydroelectric plant buffer area were selected as the segment most likely to contain the dam. A limited number of 
hydroelectric dams were not included in the results of initial spatial analysis, most often due to distances greater than 0.25 miles between the power house and the original river channel that was used to map the river in-stream data. These occurrences were handled by comparing the HSIP Electric Power Plant locations with the publically available National Inventory of Dams (NID) data locations. Where applicable, the search bounds were increased to intersect these locations with the river in-stream data. The same methodology from the initial analysis was applied to the intersected river segments within the increased search area for selecting the river segment with the greatest delta-H attribute. These segments were appended to the results from the initial spatial analysis, and all segments identified in this manner were excluded from the resource assessment.

These exclusionary criteria reduced the number of NHDPlus records from 2.9 million to 71,398 records. Figure 2.3 shows the rivers with mean discharge greater than 1,000 cfs in the contiguous United States which are included in the assessment, and the hydrologic basins by which results are aggregated for presentation. Note that several of the basins extend north into Canada and south into Mexico; however those areas were excluded from the analysis.

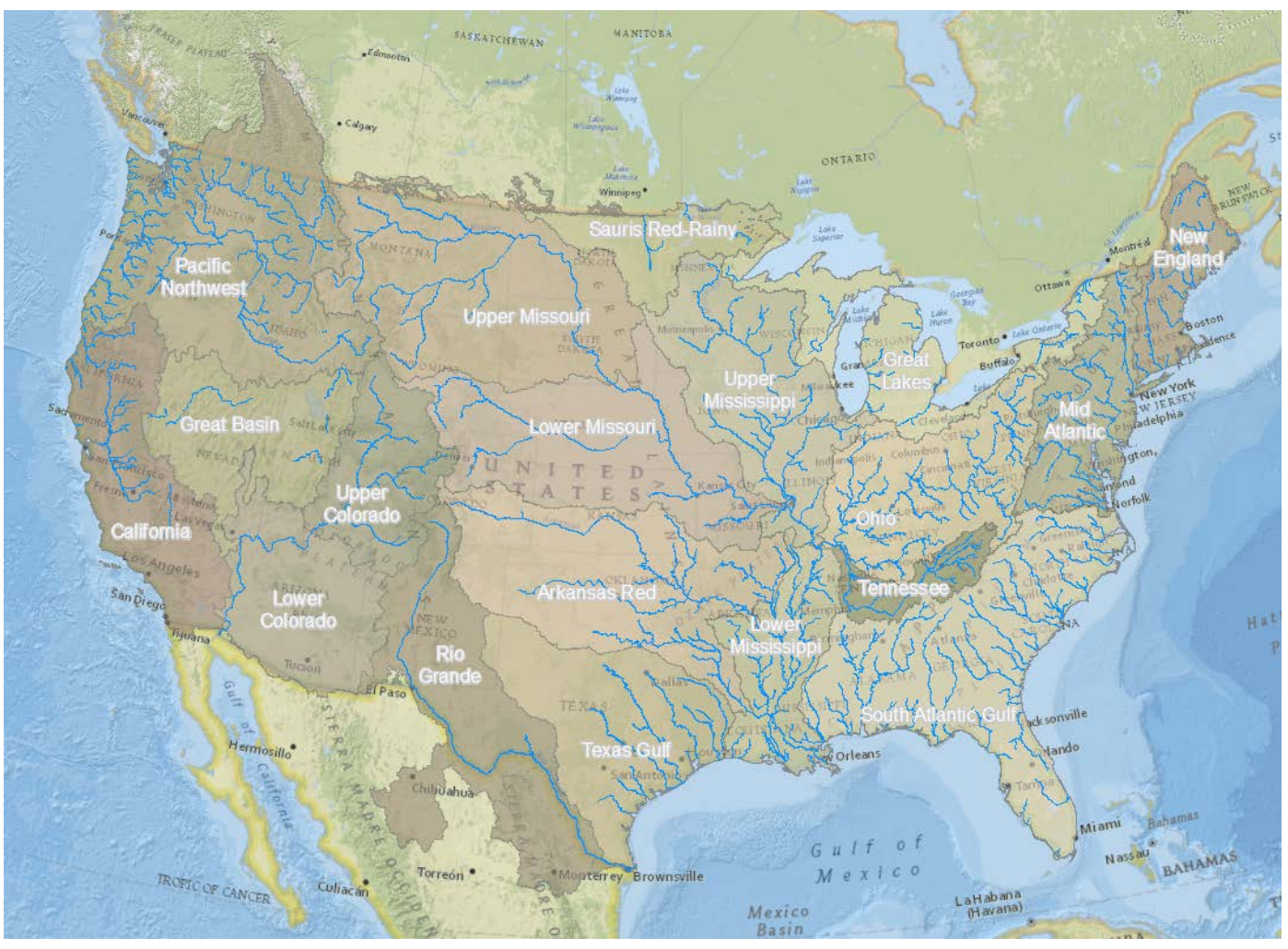

Figure 2-3

Riverine resources and hydrographic regions for which the theoretical power is calculated. 


\section{Alaska}

Since NHDPlus does not encompass Alaska, alternative sources were used to obtain input values for the theoretical power equation $(\gamma Q \Delta H)$. Average discharge data was obtained from USGS gages to the extent possible. Where USGS gage data was lacking, we obtained average discharge data from the Virtual Hydropower Prospector (the Prospector) developed for Alaska by the Idaho National Laboratory (http://hydropower.inel.gov/prospector/index.shtml). The discharge data from the Prospector and USGS gages at selected sites was generally similar. Table 2.1 compares discharge data from the Prospector and from USGS gages at four examples sites. On average, the Prospector's estimate of annual average discharge was $25 \%$ higher than that based on USGS measurements. By far, the deviation between the Prospector discharge estimate and the USGS measurement was greatest at Eagle on the Yukon River. Ignoring this outlier, the Prospector estimate was within $10 \%$ of the USGS measurement. USGS discharge measurements were used for the estimate of the theoretical resource in the Yukon River.

\section{Table 2-1}

Analysis of discharge data from the Prospector and from USGS gages for the Alaska portion of the study.

\begin{tabular}{|l|l|c|c|c|}
\hline Location & River & $\begin{array}{c}\text { Prospector } \\
\text { (cfs) }\end{array}$ & $\begin{array}{c}\text { USGS } \\
\text { (cfs) }\end{array}$ & \begin{tabular}{c} 
Difference \\
\hline Eagle
\end{tabular} \\
\hline Crooked Creek & Yukon & 148100 & 84000 & 76.3 \\
\hline Hughes & Koyukuk & 14800 & 14600 & 1.4 \\
\hline Million Dollar Bridge & Copper & 61300 & 61900 & -1.0 \\
\hline & & & Average: & $26.5 \%$ \\
\hline
\end{tabular}

Hydraulic head change in the river segments was estimated based on river surface elevations from the Prospector or from Google Earth. A comparison of surface elevations from the Prospector and Google Earth indicated they yield similar results (Table 2.2). The discharge at the segment ends (which differed significantly in some instances) was averaged to obtain the segment discharge for the theoretical power calculation. 
Table 2-2

Analysis of elevation change data from Google Earth and from the Prospector for the Alaska portion of the study.

\begin{tabular}{|l|l|c|c|c|}
\hline \multicolumn{1}{|c|}{$\begin{array}{c}\text { Segment } \\
\text { Start }\end{array}$} & \multicolumn{1}{|c|}{$\begin{array}{c}\text { Elevation } \\
\text { Segment } \\
\text { End }\end{array}$} & $\begin{array}{c}\text { Elevation } \\
\text { Google Earth } \\
\mathbf{( m )}\end{array}$ & $\begin{array}{c}\text { Elevation } \\
\text { Difference from } \\
\text { the Prospector } \\
\mathbf{( m )}\end{array}$ & $\begin{array}{c}\text { Percent } \\
\text { Difference }\end{array}$ \\
\hline $\begin{array}{l}\text { Eagle, } \\
\text { Yukon River }\end{array}$ & $\begin{array}{l}\text { Stevens Village, } \\
\text { Yukon River }\end{array}$ & 224.4 & 221.1 & 1 \\
\hline $\begin{array}{l}\text { Crooked Creek, } \\
\text { Kuskokwim River }\end{array}$ & $\begin{array}{l}\text { Bethel, } \\
\text { Kuskokwim River }\end{array}$ & 41.2 & 40.4 & 2 \\
\hline $\begin{array}{l}\text { Talkeetna, Susitna } \\
\text { River }\end{array}$ & $\begin{array}{l}\text { Mouth of Susitna } \\
\text { River, Cook Inlet }\end{array}$ & 99.7 & 107.0 & -7 \\
\hline
\end{tabular}

This methodology was first used to estimate the theoretical power for segments with mean discharge exceeding approximately $10,000 \mathrm{cfs}$ in the following major rivers:

- Yukon

- Porcupine

- Kuskokwim

- Tanana

- Susitna

- Colville

- Stikine

- Kvichak

- Nushagak

- Noatak

- Copper

In order to estimate the theoretical resource in Alaska for flows between 1,000 cfs and 10,000 cfs, an analysis of the contribution to the theoretical resource from segments with discharge above and below 10,000 cfs was conducted for the 19 hydrologic regions in the NHDPlus database (which was available for the contiguous US). For each of the 19 regions in the NHDPlus database, the ratio of the theoretical power from flows above 10,000 cfs to power from flows above $1,000\left(\mathrm{R}_{10,000 / 1,000}\right)$ was determined. Further, that ratio was examined as a function of the maximum annual flow rate in the region (Figure 2.4). It was anticipated that regions with very large rivers (e.g., the Lower Mississippi) would have a relatively large fraction of its theoretical resource coming from segments with flow rate above 10,000 cfs. Hence, $R_{10,000 / 1,000}$ would be quite high approaching 1 . The data in Figure 2.4 confirms this idea. Based on the logarithmic regression equation in the figure, and given a maximum annual discharge in Alaska of 
$272,000 \mathrm{cfs}, \mathrm{R}_{10,000 / 1,000}$ for Alaska was estimated to be 0.75 . Finally, the theoretical resource (for $\mathrm{Q}>1,000 \mathrm{cfs}$ ) was estimated to be 1.33 times the theoretical resource for discharges greater than 10,000 cfs.

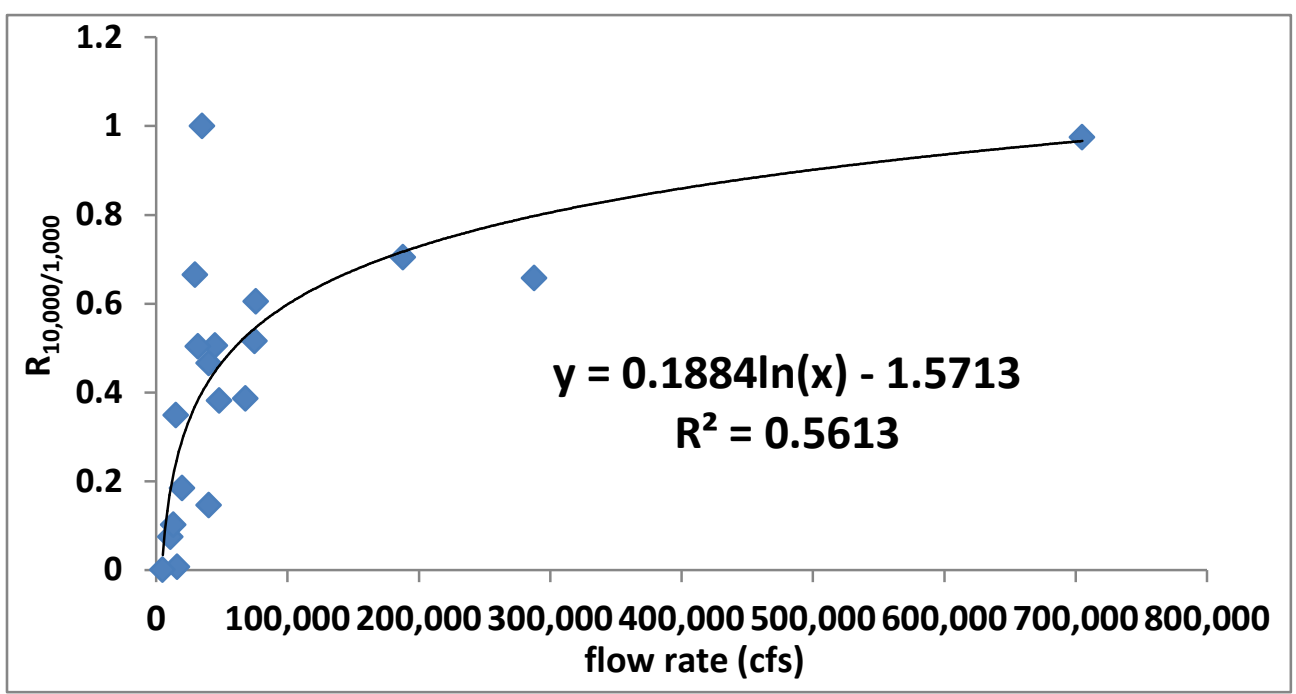

Figure 2-4

Ratio of the theoretical power from flows above 10,000 cfs to power from flows above 1,000 $\left(R_{10,000 / 1,000}\right)$ for the 19 hydrologic regions of the contiguous US as a function of maximum annual discharge rate in that region.

An alternative estimate of $\mathrm{R}_{10,000 / 1,000}$ for Alaska would be to ignore the dependence of the ratio on discharge and simply determine $\mathrm{R}_{10,000 / 1,000}$ considering all of the regions of the contiguous US. In that case, the ratio would be 0.615 and the aggregate estimate for Alaska segments with discharge exceeding 10,000 cfs would be multiplied by 1.63 to obtain an estimate of statewide theoretical power in segments exceeding 1,000 cfs. Given the relatively high $\mathrm{R}^{2}$ value in Figure 2.4, the former approach was adopted. 



\section{Section 3: Results for Theoretically Available Hydrokinetic Resource}

The estimate of the theoretical resource for the continental United States (contiguous 48 states and Alaska) totals 1,381 TWh/yr (Table 3.1). Collectively, the Pacific Northwest, Lower Mississippi, and Alaska regions comprise $54 \%$ of the total estimated theoretical resource. Appendix $\mathrm{C}$ reports the theoretical resource estimates for the major rivers in Alaska. Expansion of the results detailed in Appendix $\mathrm{C}$ to account for the theoretical power in rivers of discharge between 10,000 and 1,000 cfs as described in Section 2 yields a total Alaska resource estimate of approximately $235 \mathrm{TWh} / \mathrm{yr}$. The Yukon River had a theoretical resource of $80.5 \mathrm{TWh} / \mathrm{yr}$ and was the largest contributor to Alaska's hydrokinetic power potential.

Table 3-1

Theoretical power (annual energy) presented in units of terawatt hours per year aggregated by hydrologic regions that are depicted in Figure 3.1 and Alaska.

\begin{tabular}{|l|c|}
\hline \multicolumn{1}{|c|}{ Hydrologic Region } & $\begin{array}{c}\text { Theoretical Power } \\
\text { (Annual Energy }, \mathbf{T W h} / \mathbf{y r})\end{array}$ \\
\hline New England & 14.4 \\
\hline Mid Atlantic & 33.5 \\
\hline South Atlantic Gulf & 38.5 \\
\hline Great Lakes & 6.2 \\
\hline Ohio & 79.2 \\
\hline Tennessee & 20.4 \\
\hline Sauris Red-Rainy & 1.8 \\
\hline Upper Mississippi & 47.0 \\
\hline Lower Mississippi & 208.8 \\
\hline Texas Gulf & 8.9 \\
\hline Arkansas Red & 45.1 \\
\hline Lower Missouri & 79.8 \\
\hline
\end{tabular}


Table 3-1 (continued)

Theoretical power (annual energy) presented in units of terawatt hours per year aggregated by hydrologic regions that are depicted in Figure 3.1 and Alaska.

\begin{tabular}{|l|c|}
\hline \multicolumn{1}{|c|}{ Hydrologic Region } & $\begin{array}{c}\text { Theoretical Power } \\
\text { (Annual Energy }, \mathbf{T W h} / \mathbf{y r})\end{array}$ \\
\hline Upper Missouri & 74.3 \\
\hline Rio Grande & 29.5 \\
\hline Lower Colorado & 57.6 \\
\hline Upper Colorado & 46.9 \\
\hline Great Basin & 6.9 \\
\hline California & 50.9 \\
\hline Pacific Northwest & 296.7 \\
\hline Alaska & 235 \\
\hline Total & $\mathbf{1 , 3 8 1}$ \\
\hline
\end{tabular}




\section{Section 4: Methodology for Estimating the Technically Recoverable In- Stream Hydrokinetic Resource}

The technically recoverable in-stream hydrokinetic resource can be broadly defined as the amount of power that could be recovered given existing technologies. The technically recoverable resource is operationally defined by the methodology for estimating the fraction of the theoretically available resource that is technically recoverable. We refer to the scalar applied to the theoretical resource as the "recovery factor". The recovery factor, which is a function of the river slope and average discharge, was evaluated and applied by river segment. The technically recoverable resource was determined by assigning a recovery factor to each river segment in the database and determining the product of the recovery factor and the theoretical resource, and summing across segments.

A number of studies and reviews address the recoverable hydrokinetic resource in tidal settings (e.g., Couch and Bryden 2004, Garrett and Cummins 2005, Bryden and Couch 2006, EPRI 2006, Garrett and Cummins 2007, Lunden and Bahaj 2007, Sutherland et al. 2007, Blanchfield et al. 2008, Garrett and Cummins 2008, Karsten et al. 2008, Polagye et al. 2008, Sun et al. 2008, Walkington and Burrows 2009, Atwater and Lawrence 2010, Shapiro 2010, Defne et al. 2011, Yang and Wang 2011); however, there is no known, definitive study published on the recoverable river in-stream hydrokinetic resource other than the 1986 study by Miller et al. Ortgega-Achury et al. (2010) specifically addressed riverine hydrokinetics as well as other hydrokinetic technologies, but focused on the hydraulic and environmental consequences of turbine deployment rather than on the amount of recoverable energy in rivers.

One of the first studies to address energy extraction in a tidal context (Garrett and Cummins 2005) examined a constricted channel connecting two large bodies of water in which the tides at both ends were assumed to be unaffected by the currents through the channel. The turbines were assumed to be a uniform "fence" deployed across the channel. By assuming the water level difference between channel entrance and exit to be $a \cos w t$ (where $w$ is the angular frequency and $a$ is the tidal amplitude), Garrett and Cummins determined a maximum average power available of approximately: $0.22 \gamma a Q_{\max }$, where $\mathrm{Q}_{\max }$ is the maximum volumetric discharge in the channel (with no devices present). Given the resemblance of the Garrett and Cummins expression to our equation for the 
theoretical resource (Eq. 1.1), it would be tempting to assume that $22 \%$ of the riverine theoretical resource is recoverable. That is, 0.22 might be taken as a first estimate of the riverine recovery factor. The nature of tidal and riverine channels and their respective flows, however, are fundamentally different. For example, unsteady flow and flow acceleration are critically important characteristics of tidal flow. Furthermore, in their treatment of the tidal problem, Garrett and Cummins (2005) included flow separation as the flow exits the channel. Riverine channel flow, however, readily can be treated as steady, non-accelerating flow without flow separation issues. Tidal and riverine flows also differ very dramatically in the way they will respond to deployments of increasing numbers of hydrokinetic devices. Garrett and Cummins (2005) explain that in tidal channels, the discharge tends to decrease as the number of devices becomes excessively large. In contrast, discharge is independent of the number (or density) of devices deployed in a riverine channel. Finally, while Garrett and Cummins (2005) establish the theoretical resource for a tidal system under the conditions assumed, it does not address the technically recoverable energy by accounting for factors such as minimum flow depths and velocities and spatial constraints on turbine deployment.

This project determines the recovery factor for riverine channels based on fundamental river hydraulic principles, and incorporates realistic depth, velocity, and device spacing constraints developed in consultation with device and project developers.

The recovery factor methodology assumes a simplified geometry - a "V" shaped river cross-section - with a side-slope of 0.06 based on the measured cross-river geometries of 21 river cross-sections (4 from the Mississippi River, 5 from the Columbia River, 3 from the Snake River, 4 from the Connecticut River, 2 from the Savannah River, 2 from the Willamette River, and 1 from the Kuskokwim River). Assuming a $\mathrm{V}$-shaped channel and a single side slope value is somewhat arbitrary; however, the sensitivity study described in Section 6 indicates that the recovery factor is relatively insensitive to side slope. The recovery factor methodology also assumes a cumulative distribution function for "normalized" discharge (discharge divided by the average discharge). The cumulative distribution function for normalized discharge was based on USGS statistics for the Mississippi River at Vicksburg, Mississippi (Table 4.1). Flow statistics from a lower Mississippi River gage were chosen since the lower Mississippi is the dominant source of US hydrokinetic energy. River bottom roughness is represented using a Manning roughness coefficient (n) of $0.03 \mathrm{~s} \mathrm{~m}^{-1 / 3}$. 
Table 4-1

Discharge statistics assumed for recovery factor calculations based on measured discharge statistics from Vicksburg on the Mississippi River. The normalized discharge is the discharge relative to the annual average $\left(17,000 \mathrm{~m}^{3} / \mathrm{s}\right)$.

\begin{tabular}{|c|c|}
\hline Discharge percentile & Normalized Discharge \\
\hline $5 \%$ & 0.18 \\
\hline $25 \%$ & 0.34 \\
\hline $50 \%$ & 0.60 \\
\hline $75 \%$ & 1.18 \\
\hline $95 \%$ & 3.18 \\
\hline
\end{tabular}

Recovery Factors were calculated for selected combinations of 7 river slopes $(0.005,0.002,0.001,0.0005,0.0003,0.0001,0.00002)$ and 7 discharges $(20000$, $10000,3000,1000,400,200$, and $100 \mathrm{~m}^{3} / \mathrm{s}$, Table 4.2) in three steps. First, the power theoretically available over a $1000 \mathrm{~m}$ length of channel was determined using Eq. 1 from Section $2\left(P_{t h}=\gamma Q \Delta H\right)$. Next, the technically recoverable power was determined (following the procedure described below). Finally, the ratio of the technically recoverable to theoretically available power was determined. Note that not all 49 combinations of discharge and slope were evaluated. Some scenarios were skipped either because it was clear prior to evaluation that they were well outside of the envelope of conditions suitable for turbine deployment (i.e., too shallow) or because they constituted unrealistic or rare conditions (e.g., high slope in combination with high discharge).

The technically recoverable power was determined using a HEC-RAS flow model. The first step was to determine the portion of the channel cross-section in which flow velocity and depth would be sufficient for hydrokinetic device deployment. An expert panel, convened in Washington D.C., during April 2011 advised that velocity and depth should exceed $0.5 \mathrm{~m} / \mathrm{s}$ and $2 \mathrm{~m}$, respectively, during low ( $5^{\text {th }}$ percentile) flow conditions. Using the idealized ("V" shaped) channel, the distribution of velocity and water depth for the 5-percentile flow $\left(\mathrm{Q}_{5}\right)$ was calculated using the HEC-RAS model. Figure 4.1 below shows an example calculation of the distribution of velocity and depth for $\mathrm{Q}_{5}=1,800 \mathrm{~m}^{3} / \mathrm{s}$ and river slope $=0.0001$. The average flow rate was $10,000 \mathrm{~m}^{3} / \mathrm{s}$. Areas of insufficient depth $\left(\mathrm{h}_{5}<2 \mathrm{~m}\right)$ or insufficient velocity $\left(\mathrm{V}_{5}<0.5 \mathrm{~m} / \mathrm{s}\right)$ were designated in HEC-RAS as the "left bank" and "right bank". Here, $\mathrm{h}_{5}$ and $\mathrm{V}_{5}$ refer to the 5-percentile depth and depth-averaged velocity, respectively. 


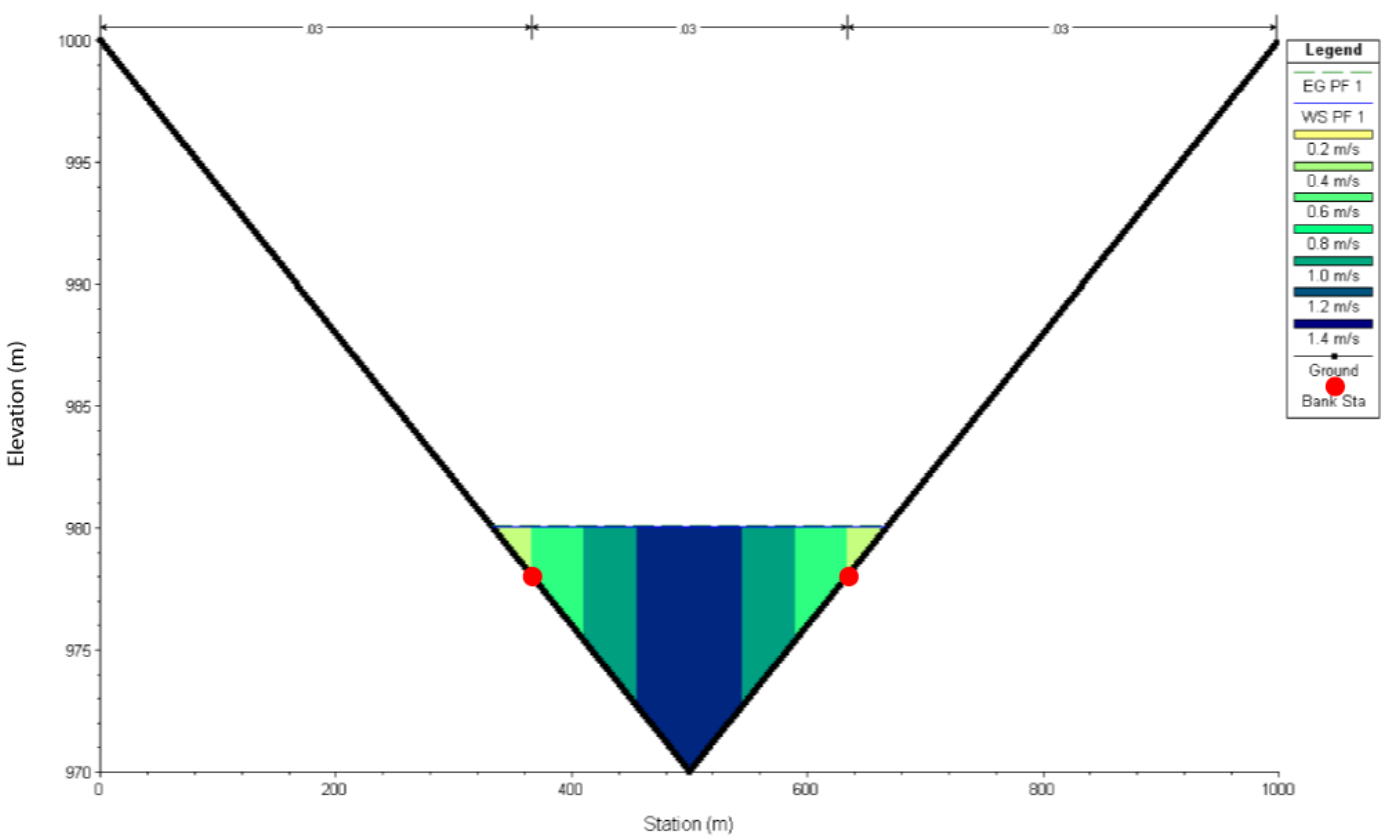

Figure 4-1

Display of calculated velocity and depth in idealized "V-shaped" channel for $Q_{5}=$ $1800 \mathrm{~m}^{3} / \mathrm{s}$ and river slope $=0.0001$. The red dots indicate the left and right bank areas.

Secondly, hydrokinetic devices were deployed (virtually) in the portion of the river cross-section with sufficient depth and velocity (i.e., between the red dots in Figure 4.1). Note, in this instance, deployment in the left and right bank areas is restricted due to depth limitations. The devices were deployed according to "rule of thumb" spacing. Specifically, it was assumed that devices would be deployed in rows. Rows of devices were separated by a distance of $10 \mathrm{D}$ where $\mathrm{D}$ is the device diameter. Devices in a given row were separated by $2 \mathrm{D}$. The device diameter was assumed to be $80 \%$ of the average depth in deployment area (at the 5 percentile flow). The presence of the hydrokinetic devices would slow the flow of water in the channel (i.e., cause "back effects"). To determine these back effects, the presence of hydrokinetic devices was represented within HEC-RAS by computing an effective bottom-roughness. The effective roughness (referred to as $n_{t}$ ) was determined based on the roughness of the natural channel bottom (n), the energy extraction of the hydrokinetic devices, and additional energy losses associated with the mixing of the low velocity wake water with high velocity water outside the wake. Based on a series of hydraulic calculations (Appendix B, Kartezhnikova and Ravens in review), it was determined that:

$$
n_{t}=n \cdot\left(b^{1 / 3}-0.28263 \cdot b^{-1 / 3}+0.139296\right)^{5 / 3}
$$

where:

$$
\begin{aligned}
& b=0.46088 \cdot a+\left((0.46088 \cdot a+0.68368)^{2}+0.022578\right)^{1 / 2}+0.68368 \\
& \mathrm{a}=\left(\frac{3}{4} \frac{\xi(1+\epsilon)}{n^{2} g} \cdot \frac{N A_{r}}{w L}\right) \cdot h^{1 / 3} \\
& \quad<4-4>
\end{aligned}
$$


$\xi$ is device efficiency,

$\epsilon$ is blockage ratio (fraction of river cross-section occupied by devices),

$\mathrm{N}$ is the number of devices in the river segment under consideration,

$A_{r}\left(m^{2}\right)$ is the frontal (or swept) area of the device,

$\mathrm{h}(\mathrm{m})$ is water depth,

$\mathrm{w}(\mathrm{m})$ is the width of the river or channel that is occupied by devices, and

$\mathrm{L}(\mathrm{m})$ is the segment length.

Note, recent research (Ravens et al. in preparation) has shown that hydraulic impacts of hydrokinetic device deployments - as calculated using the enhanced roughness approach - are in agreement with hydraulic impacts as calculated using EFDC-based software developed by Sandia Labs (Jesse Roberts, Sandia National Laboratory; personal communication). Using the enhanced bottom roughness $\left(\mathrm{n}_{\mathrm{t}}\right)$ to represent the devices, the average velocity $(\mathrm{V}, \mathrm{m} / \mathrm{s})$ in the device deployment area was computed for the 5-, 25-, 50-, 75-, and 95-percentile flow rates (Table 4.1). In addition, the extracted power (i.e., technically available power) for each flow rate was calculated using:

$$
P_{\text {tech }}=\xi \frac{\rho}{2} V^{3}\left(N A_{r}\right)
$$

Finally, the ratio of the technically recoverable power to theoretically available power (i.e., the recovery factor) was calculated for each discharge. The recovery factor at a given river segment was observed to decrease with increasing discharge. For example, the recovery factor for the various discharges is provided for a channel with an average discharge of 10,000 and for a slope of 0.0005 (Table 4.2). The weighted average recovery factor is 0.24 which is approximated by the recovery factor for the 50-percentile discharge. Table 4.2 also reports the average flow depth in the deployment area with and without hydrokinetic devices deployed. The data shows that the impact of the devices on water level increases with flow rate. Finally, Table 4.2 shows how the blockage ratio - the ratio of the turbine swept area to the cross-sectional area - varies with flow rate (at a given location). Three calculations of blockage ratio are provided in Table 4.2. 
Table 4-2

Variation of Recovery Factor with discharge for a V-shaped channel with an annual average flow rate of $10,000 \mathrm{~m}^{3} / \mathrm{s}$ and a slope of 0.0005 .

\begin{tabular}{|c|c|c|c|c|c|}
\hline Flow percentile & $Q_{5}$ & $Q_{25}$ & $Q_{50}$ & $Q_{75}$ & $Q_{95}$ \\
\hline Flow rate $\left(\mathrm{m}^{3} / \mathrm{s}\right)$ & 1,800 & 3,400 & 6,000 & 11,800 & 31,800 \\
\hline Recovery Factor & 0.28 & 0.27 & 0.24 & 0.21 & 0.16 \\
\hline $\begin{array}{l}\text { Average depth }(m) \text { in deployment area with } \\
\text { no devices. }\end{array}$ & 4.68 & 6.59 & 8.80 & 12.19 & 19.1 \\
\hline $\begin{array}{l}\text { Average depth }(m) \text { in deployment area with } \\
\text { devices. }\end{array}$ & 5.79 & 7.96 & 10.40 & 14.03 & 21.26 \\
\hline $\begin{array}{l}\text { Blockage ratio in deployment area } \\
\text { neglecting back effects }\end{array}$ & 0.209 & 0.148 & 0.111 & 0.080 & 0.051 \\
\hline $\begin{array}{l}\text { Blockage ratio in deployment area } \\
\text { accounting for back effects }\end{array}$ & 0.169 & 0.123 & 0.094 & 0.070 & 0.046 \\
\hline $\begin{array}{l}\text { Blockage ratio in the river cross-section } \\
\text { accounting for back effects }\end{array}$ & 0.147 & 0.093 & 0.061 & 0.038 & 0.018 \\
\hline
\end{tabular}

The recovery factors for 32 flow and slope scenarios are provided in Table 4.3. The recovery factors in Table 4.3 were estimated based on the recovery factor for the 50-percentile flow. Table 4.3 also displays the average water depth in the deployment area with and without devices at the 50-percentile flow rate for selected scenarios. The data shows that the impact of devices is greatest when the discharge is greatest. 
Table 4-3

Discharge - river slope scenarios and recovery factor calculation results. $N D=$ no data.

\begin{tabular}{|c|c|c|c|c|}
\hline $\begin{array}{c}\begin{array}{c}\text { Annual } \\
\text { average flow } \\
\text { rate }\left(\mathrm{m}^{3} / \mathrm{s}\right)\end{array} \\
\end{array}$ & Slope & $\begin{array}{c}\text { Recovery } \\
\text { factor }\end{array}$ & $\begin{array}{c}\text { Average depth }(\mathrm{m}) \\
\text { in deployment } \\
\text { area with no } \\
\text { devices (at } Q_{50} \text { ) }\end{array}$ & $\begin{array}{c}\text { Average depth } \\
(\mathrm{m}) \text { in deployment } \\
\text { area with devices } \\
\text { (at } \mathrm{Q}_{50} \text { ) }\end{array}$ \\
\hline 10000 & 0.001 & 0.23 & ND & ND \\
\hline 3000 & 0.001 & 0.17 & ND & ND \\
\hline 3000 & 0.005 & 0.13 & ND & ND \\
\hline 1000 & 0.005 & 0 & - & - \\
\hline 10000 & 0.002 & 0.22 & ND & ND \\
\hline 3000 & 0.002 & 0.16 & ND & ND \\
\hline 1000 & 0.002 & 0.07 & 3.61 & 3.77 \\
\hline 700 & 0.002 & 0.03 & 3.3 & 3.36 \\
\hline 400 & 0.002 & 0 & - & - \\
\hline 1000 & 0.001 & 0.09 & 4.0 & 4.23 \\
\hline 700 & 0.001 & 0.06 & 3.63 & 3.79 \\
\hline 400 & 0.001 & 0 & - & - \\
\hline 10000 & 0.0005 & 0.24 & 8.80 & 10.40 \\
\hline 3000 & 0.0005 & 0.19 & 6.04 & 6.84 \\
\hline 1000 & 0.0005 & 0.12 & 4.39 & 4.74 \\
\hline 400 & 0.0005 & 0.04 & 3.45 & 3.55 \\
\hline 200 & 0.0005 & 0 & - & - \\
\hline 20000 & 0.0003 & 0.27 & 12.14 & 14.78 \\
\hline 10000 & 0.0003 & 0.25 & 9.59 & 11.42 \\
\hline 1000 & 0.0003 & 0.14 & 4.68 & 5.11 \\
\hline 500 & 0.0003 & 0.09 & 3.88 & 4.10 \\
\hline 200 & 0.0003 & 0 & - & - \\
\hline 20000 & 0.0001 & 0.28 & 14.64 & 17.67 \\
\hline 10000 & 0.0001 & 0.27 & 11.52 & 14.0 \\
\hline 1000 & 0.0001 & 0.18 & 5.52 & 6.20 \\
\hline 200 & 0.0001 & 0.04 & 3.52 & 3.58 \\
\hline 100 & 0.0001 & 0 & - & - \\
\hline 20000 & 0.00002 & 0.24 & 21.63 & 25.88 \\
\hline 10000 & 0.00002 & 0.23 & 16.96 & 19.85 \\
\hline 3000 & 0.00002 & 0.09 & 11.94 & 12.38 \\
\hline 1000 & 0.00002 & 0.02 & 8.59 & 8.64 \\
\hline 100 & 0.00002 & 0 & - & - \\
\hline
\end{tabular}


Based on these data, an expression was developed to relate recovery factor (RF) to annual average flow rate $\left(\mathrm{Q}_{2} \mathrm{~m}^{3} / \mathrm{s}\right)$ and slope $(\mathrm{S})$ :

$$
\begin{aligned}
& R F=\frac{0.002647(Q-200)^{0.3426}}{\sqrt{62.4277 S^{2}}} e^{\frac{-(\log (S)-1.498)^{2}}{19.87}} \quad \text { if } Q>200 \quad \text { Eq. 4-3 } \\
& R F=0 \quad \text { if } Q \leq 200
\end{aligned}
$$

This expression explains $88 \%$ of the variance in recovery factor for the set of scenarios in Table 4.3. Two viewpoints of a surface plot of the RF expression and the data points in Table 4.3 are depicted in Figure 47h.5The expression was used to calculate segment-specific recovery factors and estimate the technically recoverable hydrokinetic energy resource throughout the contiguous 48 states.
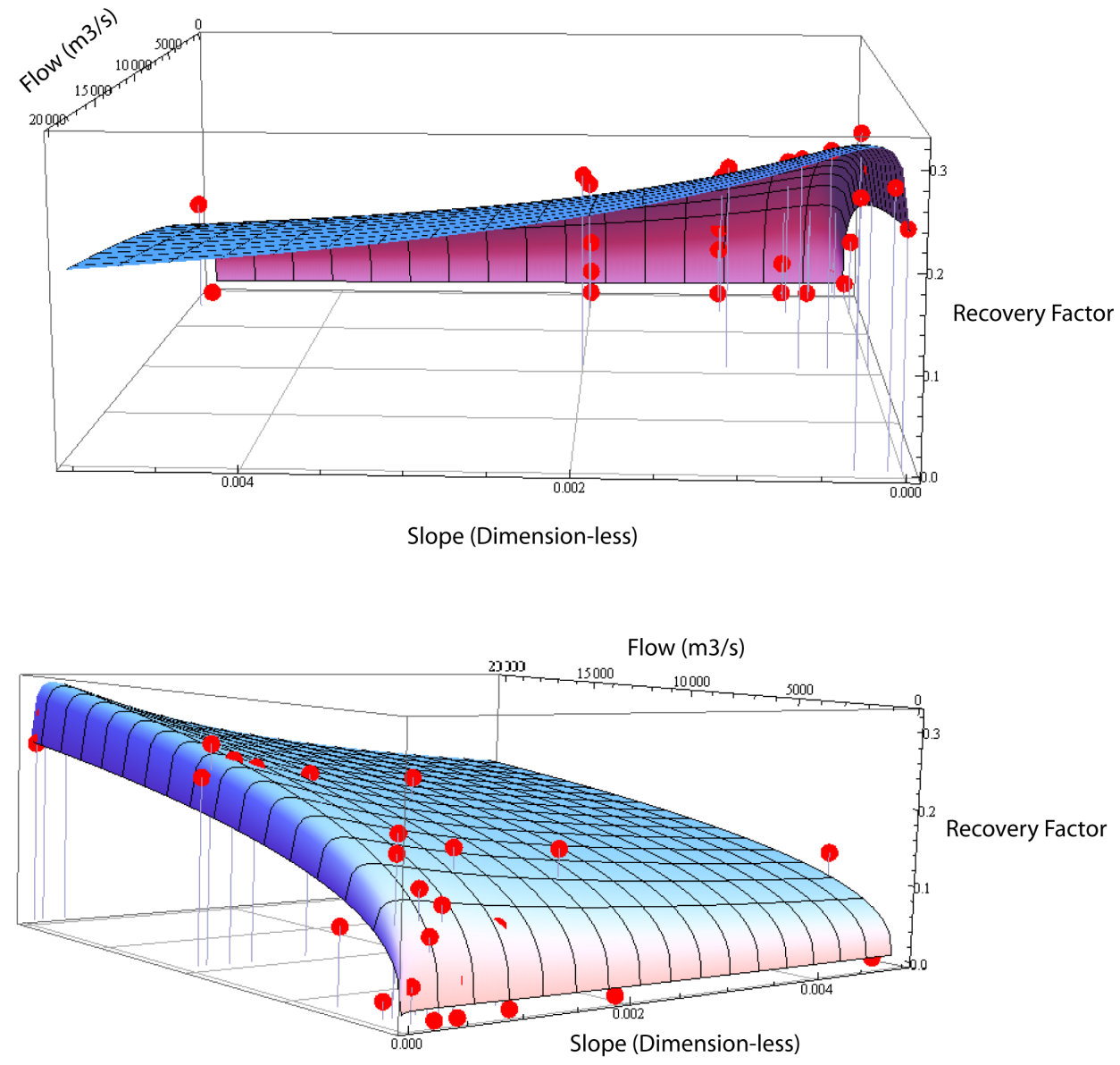

Figure 4-2

Two views of a plot of the Recovery Factor scenario results (data points) listed in Table 4.3 and fitted Recovery Factor function (surface plot). 
For Alaska, data on river slope was not readily available. Hence, the Recovery Factor was estimated based on the flow rate alone using:

$$
R F=0.0557 \ln (Q)-0.2946 \quad \text { Eq. } 4-4
$$

The above equation (with an $\mathrm{R}^{2}$ of 0.78 ) was obtained from the Recovery Factor and flow rate data from Table 4.3. The relationship between annual average flow rate and recovery factor is displayed in Figure 4.3 below.

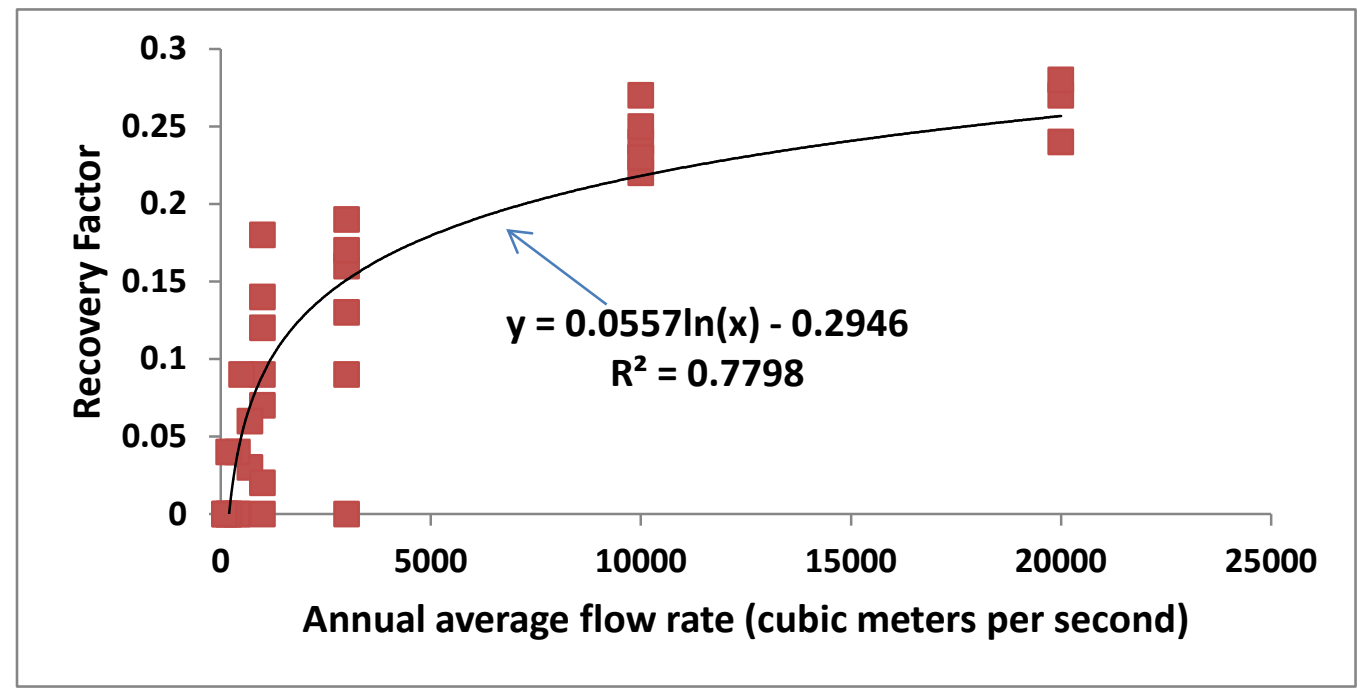

Figure 4-3

Plot showing the relationship between Recovery Factor and discharge based on data in Table 4.3.

This recovery factor function was applied to the discharge data for individual river segments identified in Appendix $\mathrm{C}$ to estimate the technically recoverable in-stream hydrokinetic power for those Alaska river segments with average discharge greater than $10,000 \mathrm{cfs}$. 



\section{Section 5: Results for the Technically Recoverable Hydrokinetic Resource}

The technically recoverable resource is presented by hydrologic region in Table 5.1. The total estimated technically recoverable power is $120 \mathrm{TWh} / \mathrm{yr}$. The Lower Mississippi region contributes nearly half (47.9\%) of the total resource estimate. The major rivers of Alaska constitute $17.1 \%$ of the total for the continental U.S. The next largest contributor is the Pacific Northwest region, which contributes $9.2 \%$, followed by the Ohio region (5.7\%). Collectively these four regions encompass $80 \%$ of the technically recoverable hydrokinetic resource in the continental U.S.

Table 5-1

Technically recoverable hydrokinetic resource for the continental United States, by hydrologic region depicted in Figure 3.1 and for Alaska.

\begin{tabular}{|l|c|c|}
\hline Hydrologic Region & $\begin{array}{c}\text { Technically } \\
\text { Recoverable Annual } \\
\text { Energy }\end{array}$ & $\begin{array}{c}\text { Portion of Total } \\
\text { Technically }\end{array}$ \\
\hline New England & 0.2 & $\begin{array}{c}\text { Recoverable Resource } \\
\text { (\%) }\end{array}$ \\
\hline Mid Atlantic & 1.0 & 0.2 \\
\hline South Atlantic Gulf & 1.2 & 0.8 \\
\hline Great Lakes & 0.01 & 1.0 \\
\hline Ohio & 6.9 & 0.2 \\
\hline Tennessee & 1.0 & 5.7 \\
\hline Sauris Red-Rainy & 0.03 & 0.9 \\
\hline Upper Mississippi & 5.1 & 0.03 \\
\hline Lower Mississippi & 57.4 & 4.2 \\
\hline Texas Gulf & 0.05 & 47.9 \\
\hline Arkansas Red & 1.3 & 0.04 \\
\hline Lower Missouri & 5.6 & 1.0 \\
\hline
\end{tabular}


Table 5-1 (continued)

Technically recoverable hydrokinetic resource for the continental United States, by hydrologic region depicted in Figure 3.1 and for Alaska.

\begin{tabular}{|l|c|c|}
\hline Hydrologic Region & $\begin{array}{c}\text { Technically } \\
\text { Recoverable Annual } \\
\text { Energy (TWh/yr) }\end{array}$ & $\begin{array}{c}\text { Portion of Total } \\
\text { Technically } \\
\text { Recoverable Resource } \\
\text { (\%) }\end{array}$ \\
\hline Upper Missouri & 2.8 & 2.3 \\
\hline Rio Grande & 0.3 & 0.2 \\
\hline Lower Colorado & 3.9 & 3.2 \\
\hline Upper Colorado & 1.1 & 0.9 \\
\hline Great Basin & 0 & 0 \\
\hline California & 0.7 & 0.6 \\
\hline Pacific Northwest & 11.0 & 9.2 \\
\hline Alaska & 20.5 & 17.1 \\
\hline Total & $\mathbf{1 1 9 . 9}$ & \\
\hline
\end{tabular}




\section{Section 6: Uncertainty of the estimates of the Theoretical and Technically Recoverable Hydrokinetic Resource}

Uncertainty in the theoretical resource is directly related to uncertainty in the discharge and in the river slope as is evident in Eq. 1.1. The project team examined uncertainty of the total theoretical resource estimate as well as uncertainty of the theoretical resource estimate in individual river segments. The uncertainty of the overall resource estimate was judged to be relatively small. The team examined river elevation change between the headwaters and the river mouth as represented by NHDPlus and as estimated by an alternative source (Table 6.1). The NHDPlus data was in good agreement with the alternative data so it was judged that river slope uncertainty would not contribute significantly to overall uncertainty in the resource estimate at the scale of entire rivers. For individual segments, however, the percent errors can be larger.

Table 6-1

Uncertainty analysis of river elevation change between headwaters and mouth

\begin{tabular}{|c|c|c|c|c|}
\hline River & $\begin{array}{c}\text { NHDPlus } \\
\text { elevation change } \\
(\mathbf{m})\end{array}$ & $\begin{array}{l}\text { Alternative } \\
\text { elevation change } \\
\text { (m) }\end{array}$ & $\begin{array}{c}\text { Percent } \\
\text { difference }\end{array}$ & $\begin{array}{c}\text { Source of } \\
\text { alternative } \\
\text { data }\end{array}$ \\
\hline Colorado & 1714 & 1734 & $1 \%$ & Google Earth \\
\hline Missouri & 1180 & 1110 & $6 \%$ & $\begin{array}{l}\text { Google Earth and } \\
\text { Wikipedia }\end{array}$ \\
\hline Snake & 1986 & 1960 & $1 \%$ & Google Earth \\
\hline Arkansas & 1975 & 2000 & $1 \%$ & $\begin{array}{l}\text { Google Earth and } \\
\text { Wikipedia }\end{array}$ \\
\hline
\end{tabular}

Analysis of NHDPlus and USGS discharge data indicated that uncertainty in NHDPlus discharge data would not contribute to significant uncertainty in the overall theoretical resource estimate. Uncertainty in the NHDPlus discharge (referred to as "MAFLOWU" in the database) was studied by comparing NHDPlus discharge estimates (QNHDPlus) and USGS-gage measurements (QUSGS) 
at a representative location in each of the 36 hydrologic regions represented in the NHDPlus database (Figure 6.1). The plot of the individual data points (comparing the two estimates) and the linear regression of $\mathrm{Q}_{\mathrm{NHDPlus}}$ and QusGs both show that $Q_{\text {NHDPlus }}$ is an unbiased estimate of discharge in the river segments - assuming that USGS gage data is reasonably accurate. Note, USGS gage data has an uncertainty of about $10 \%$ for a 30 year record (Benson and Carter 1973). Hence, for the overall theoretical resource estimate, which is essentially the sum of numerous river segment discharge estimates, uncertainty in NHDPlus discharge estimates would not contribute to significant uncertainty in the overall theoretical resource estimate.

However, our analysis indicates that there is significant uncertainty in our estimates of the theoretical resource in individual river segments. In individual segments, both river slope uncertainty and discharge uncertainty contributed significantly to theoretical resource uncertainty. For example, according to NHDPlus documentation (McKay et al. 2012), in some instances, it was necessary for the NHDPlus developers to manually smooth the river slope in order to get rivers to flow in the correct direction. There is also significant uncertainty in the NHDPlus discharge in individual river segments. For example, in the data shown in Figure 6.1, the NHDPlus discharge deviated from the USGS measurement by 77\% (on average), with some minor over-estimation of discharge (in the NHDPlus estimate) at low flow rates.

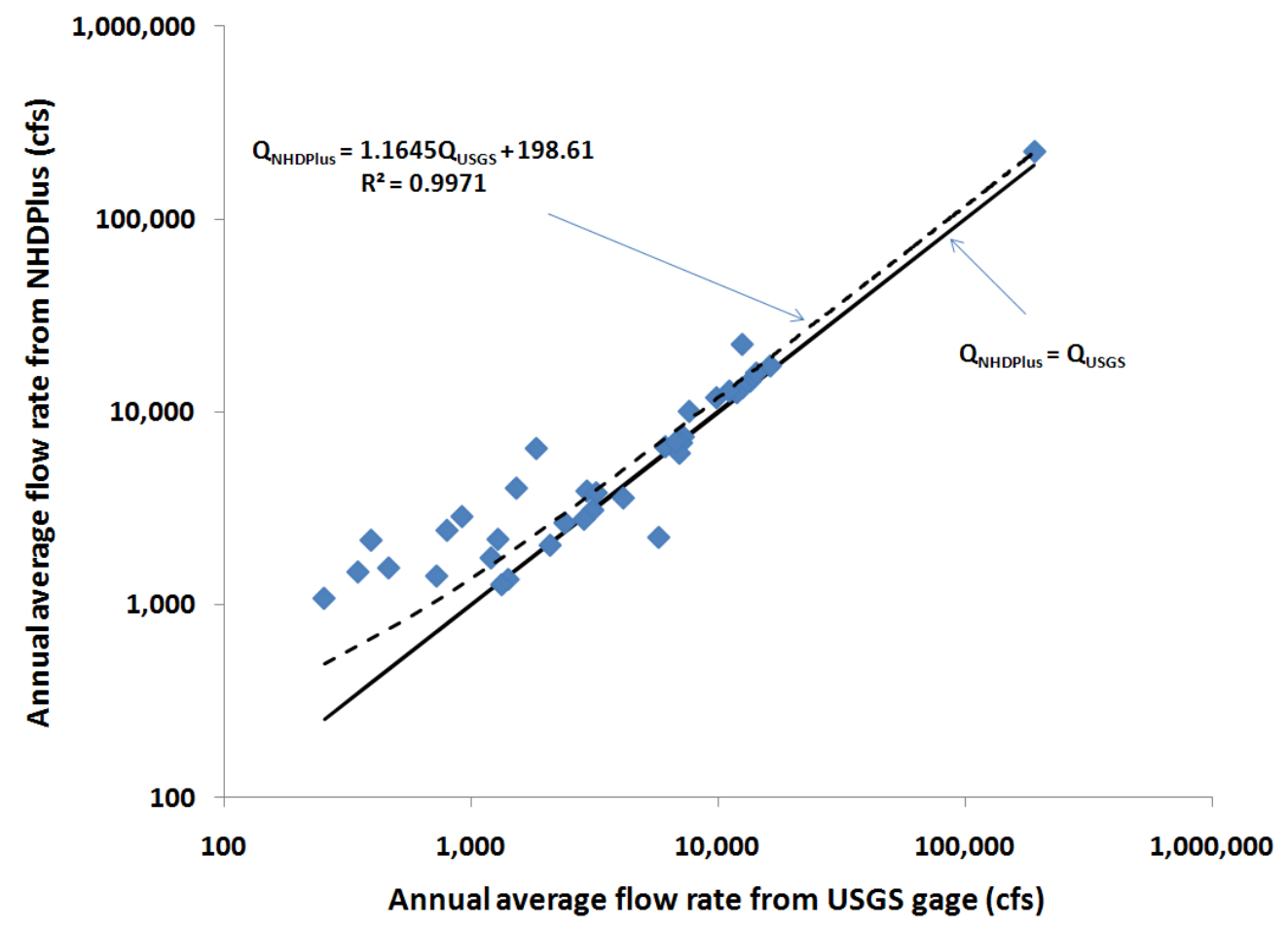

Figure 6-1

Comparison of NHDPlus-estimated discharge and USGS gage measured discharge at selected locations in each of the hydrologic regions of the US. 
The uncertainty in the estimation of the recovery factor and technical resource can be studied by examining the methodology used to estimate the recovery factor. As described in $\square \square$. \# (4, an expression for the recovery factor as a function of average discharge and as a function of river slope was developed based on a "case studies" approach. The case studies assumed a "V" - shaped channel profile with a side slope of 0.06 and it assumed normalized flow distribution curve based on flow statistics from the Mississippi River at Vicksburg Mississippi. In order to estimate the uncertainty in the recovery factor (and technical hydrokinetic resource), a number of sensitivity studies were done. These studies included:

1. A comparison of the recovery factor calculated for an idealized $V$-shaped channel (side slope $=0.021$ ) with that for a real channel with the same average side slope.

2. A comparison of the recovery factor calculated for an idealized $\mathrm{V}$-shaped channel with a side slope of 0.06 with that calculated for side slopes of 0.03 and 0.09 (using the case shown in Table 4.2 as a baseline).

3. A comparison of the recovery factor calculated assuming in-row spacing of $2 \mathrm{D}$ between devices with a spacing of $1 \mathrm{D}$ between devices.

4. A comparison of the recovery factor calculated assuming $\mathrm{Q}_{5} / \mathrm{Q}_{\mathrm{ave}}=0.18$ (Table 4.1) with the recovery factor calculated assuming $\mathrm{Q}_{5} / \mathrm{Q}_{\text {ave }}=0.35$.

5. A comparison of the recovery factor calculated assuming a Manning roughness coefficient of 0.025 instead of 0.03 .

A summary table presenting the sensitivity of Recovery Factor to effects 1 through 5 above is provided in Table 6.2 below. The sensitivity study indicates that the recovery factor for a given river segment is uncertain. Since the recovery factor and the theoretical resource in a given segment are uncertain to a large degree, it is clear that technical resource in a given segment is also quite uncertain. We can next turn our attention to the uncertainty of the overall technical resource estimate. Earlier, we argued that the estimate of the overall theoretical resource is fairly certain since there was no significant source of bias in the theoretical estimates in individual river segments. Here, we again argue that the overall theoretical resource is fairly certain since there are no significant sources of bias in the recovery factor. A potential source of bias (on the order of $16 \%)$ is the bias in NHDPlus flow rates relative to USGS gage measurements. 
Table 6-2

Sensitivity of Recovery Factor calculation

\begin{tabular}{|l|c|}
\multicolumn{1}{|c|}{ Sensitivity test } & $\begin{array}{c}\text { Sensitivity } \\
\text { (\% change from baseline) }\end{array}$ \\
\hline Use real river profiles instead of "V" shape & $15 \%$ \\
\hline Use of side slope of .03 or 0.09 instead of .06 & $-9 \%, 9 \%$ \\
\hline Device spacing of 1D (not 2D) in rows & $-4 \%$ \\
\hline$Q_{5} / Q_{\text {ave }}=.35$ instead of .18 & $16 \%$ \\
\hline Manning roughness of 0.025 instead of 0.03 & $4 \%$ \\
\hline
\end{tabular}

More insight into sources of uncertainty in this project is obtained by examining the NHDPlus database in more detail. Though NHDPlus is the best dataset for a project of this scope, it is important to note its limitations. Also NHDPlus does not exist for the State of Alaska which requires a different approach. A more detailed description of NHDPlus is at http://www.horizonsystems.com/NHDPlus/data/NHDPLUS UserGuide.pdf

The user of these data should be aware that while these data can be used to obtain a useful estimate of the hydrokinetic resource in the contiguous 48 states, as well as the broad scale distribution of the resource, the data are not suitable for identifying sites suitable for hydrokinetic project deployments. 


\section{Section 7: GIS Display}

The geo-spatial results of this assessment are available as an interactive webbased Geographic Information System (GIS) application called the River Atlas app. The River Atlas is deployed using the National Renewable Energy Laboratory's (NREL's) OpenCarto framework. OpenCarto is an open architecture framework that utilizes open source libraries (e.g., MapServer, TileCache, Ext-JS and OpenLayers), and standards such as Styled Layer Descriptor (SLD), Web Mapping Service (WMS) and Web Feature Service (WFS). OpenCarto is designed to support analysis, visualization and data exploration, and is an ideal medium for the visual representation of the riverine hydrokinetic data. Currently, results are only available for the 48 contiguous states. Results will be made available for Alaska in the future.

\section{Data Processing}

NREL received the data as GIS shapefiles along with a MXD file. The shapefiles contain the data variables and georeferenced coordinates. The MXD file was used as a reference for styling the visual representation of the data within the stand-alone application.

The shapefiles were re-projected in the WGS_1984 Geographic Coordinate System for compatibility with the OpenCarto framework. The re-projected data were then converted from shapefiles to a PostGIS object relational database.

OpenCarto can access the data from the spatial database repository, and by creating unique layers for each data variable the hydrokinetic data can be rendered in a web mapping application. The river networks are displayed as line segments reflecting the power variable in the database and classed by standard deviation. Unique layers were created for three power classes (low, medium, and high). By default, the layers are generated as simple spatial geometries with no associated style. Applied rules give each power class a line color and stroke width.

\section{Tool Functionality and Capabilities}

The River Atlas app is a web-based application that was selected as the tool to visually display the riverine hydrokinetic resource data; it is a specific application module that is hosted on the OpenCarto platform. The data are displayed by adding the layers to the application module. The river app was assigned a URL (http://maps.nrel.gov/river_atlas) to allow users to access and interact with the 
data. The basic components of the application are a map window for displaying the data, a content display window (which uses tabs to display the map layers, legend, and data sources), and a toolbar.

The River Atlas app has additional capabilities that allow the user to interact with the data and create customized visualizations and maps. The query tool provides several options that return query results from the spatial database. The data can be queried by point, region, or attribute. The query will return results from the geometry feature(s) in a new window and also highlight the selected feature(s) on the map. Region query results can be downloaded by the user as a CSV file.

OpenCarto capabilities allow users to generate their own thematic maps. The layer tree can be customized to reorder the layer index, class thresholding can be performed to display only the data of specific interest to the user, and legend and class display colors can be customized. Data results can be downloaded and customized maps can be printed if desired.

\section{Application Analysis}

The interactive capabilities of the application can be used for basic data analysis on active layers. Results for specific, user-selected geographic points or regions can be returned using the query tool. The query results can be coupled with other layers to obtain answers to questions such as estimating the resource potential in a specific county or state.

A combination of capabilities and tools can also be used to determine distance from a specified river segment. By using layer thresholding, a user can display only power values within specified numerical bounds. Then, using the measure tool, a distance from those river segments to the nearest point of interest (e.g., city or known transmission line) can be estimated.

The flexibility of the application and customization of the data allows users to perform basic analysis, and with the capability of downloading the data users can perform their own advanced analysis and modeling.

\section{Intended Audience}

The mission of DOE's Water Power Program is to perform and sponsor the necessary research, development, testing, evaluation and demonstration of innovative water power technologies leading to cost-effective environmentally responsible generation of renewable energy, including from marine and hydrokinetic $(\mathrm{MHK})$ resources.

The River Atlas app is a tool that supports attainment of this goal by providing an easy-to-use interactive visual interface. This type of interface is beneficial both to audiences who may be familiar with marine and hydrokinetic resources, and also to those who are exploring them for the first time. 
The application can deliver insight and facilitate discovery of geographic regions and riverine systems with relatively high hydrokinetic resources. While the application and supporting data are not suitable for siting studies, they may help researchers and others identify rivers meriting more in-depth data collection and siting studies. 



\section{Section 8: Conclusions}

An information base exists from which the theoretically available and technically recoverable riverine, hydrokinetic resource can be estimated for the continental United States. These data were used to make such an assessment utilizing established hydraulic engineering principles and advice from relevant experts. The resulting assessment substantially advances understanding of the hydrokinetic resource potential in the continental United States. The more detailed and comprehensive assessment reported here yields an estimate of technically recoverable hydrokinetic energy $(119.9 \mathrm{TWh} / \mathrm{yr})$ that is approximately $9 \%$ greater than the estimate from the only other nationwide assessment (i.e., Miller et al. 1986). A difference of this magnitude is not unexpected given the differences in criteria for waterbody inclusion and differences in analytical methodology. Large differences between the two studies in regional distribution of the resource can be attributed to differences in methodology as well.

The data gathering and reporting programs supplying the data, however, were not designed and implemented with hydrokinetic resource assessment as an intended application of the data. Furthermore, operating riverine hydrokinetic projects don't yet exist to provide a means of validating important assumptions incorporated into this assessment. Consequently, the assessment substantially advances understanding of the hydrokinetic resource potential of the United States; however, substantial uncertainty remains. Uncertainty and error are greatest at the scale of individual segments, and results are not appropriate for siting projects or ranking river segments. Further work is needed to develop and validate models of the hydraulic effects of hydrokinetic turbine projects. Such modeling tools are needed for refined resource assessment, project planning, and environmental impact assessment.

Improved understanding also is needed of the practical constraints on development of the hydrokinetic resource and of the impact of those constraints on the portion of the technically recoverable resource that may ultimately be exploited. Significant improvements in understanding of the hydrokinetic resource will require more detailed hydrologic information, site-specific information on constraints imposed by existing uses and environmental sensitivities, and empirical validation and refinement of hydrokinetic array models. Given the uncertainties that currently exist, the practical resource is an unknown fraction of the technically recoverable resource estimated by this study. 



\section{Appendix A: Validation}

The National Renewable Energy Laboratory's validation of the hydrokinetic energy resource values in the GIS database was different from NREL's previous validations of wind and wave power estimates. Due to the scarcity of complete stream-flow and channel cross-section information, all available information was used to help compute the in-stream resource, meaning that these data can no longer serve as an independent data set for validation. Moreover, we know of no direct measurements of in-stream energy that could be used to validate the model.

Consequently, NREL's validation effort was limited to the inspection of the estimated resource values to verify that they are reasonable, consistent over time, reproducible, and were within the statistical bounds of other naturally varying river systems.

The primary validation process consisted of a statistical analysis of the individual river segments and their contribution to the total resource. Segments were grouped by power output, power per $\mathrm{km}$, slope, flow and other measures, and the largest values in each group were inspected manually. GoogleEarth was used to determine whether high power values were caused by actual high-gradient regions or by dams that had slipped through the automated dam identification process. Segments were also grouped by river, and obvious outliers were removed. This power screening process also identified a few segments at the US-Canada border that had erroneous values of delta-h.

After removal of all anomalous segments, the remaining segments were sorted by power. The top 10 most powerful segments were all located on the Mississippi River. Almost two-thirds of the top 150 segments were on the Mississippi, followed by the Colorado, Ohio, Missouri and Columbia Rivers. A final ranking of the top power producing rivers is shown in Table A-1. 
Table A-1

Top Rivers by Power Production

\begin{tabular}{|l|c|}
\hline \multicolumn{1}{|c|}{ River } & $\begin{array}{c}\text { Theoretical Power } \\
\text { (TWh/yr) }\end{array}$ \\
\hline Mississippi River & 217.3 \\
\hline Colorado River & 79.2 \\
\hline Missouri River & 59.8 \\
\hline Snake River & 41.7 \\
\hline Ohio River & 40.5 \\
\hline Arkansas River & 29.8 \\
\hline Rio Grande & 28.5 \\
\hline Yellowstone River & 26.4 \\
\hline Columbia River & 26.3 \\
\hline Salmon River & 22.6 \\
\hline
\end{tabular}

The general order shown in this table is roughly what one would expect. The high value for the Snake River is due to a few segments with high delta-h, but these may be in error. Some high powers from the Colorado and Yellowstone Rivers are from rapids and/or waterfalls. These features are often located in national parks or other protected sites and would be removed from consideration if a complete database of environmental exclusions were applied.

As riverine hydrokinetic project siting studies and deployments accrue, data suitable for further model refinement and validation will become available. 


\title{
Appendix B: Hydraulic Impacts of Hydrokinetic Devices
}

\begin{abstract}
A simple technique to estimate the far-field hydraulic impacts associated with the deployment of hydrokinetic devices is introduced. The technique involves representing the presence of hydrokinetic devices as enhanced bottom roughness. The enhanced Manning roughness is found to be a function of the Manning roughness of the natural channel, device efficiency, blockage ratio, density of device deployment and water depth. The technique is developed assuming simple, open channel flow geometry. However, once the effective bottom roughness is determined, it can be used to determine the hydraulic impact of arbitrary device configurations and arbitrary flow situations.
\end{abstract}

\section{Introduction}

Hydrokinetic energy conversion devices are deployed in flowing water, and they extract energy according to the kinetic energy or velocity of the flowing water. The power available from hydrokinetic devices, per unit swept area, is termed the hydrokinetic power density $\left(\mathrm{PD}, \mathrm{W} \mathrm{m}^{-2}\right)$. Hydrokinetic power density is a function of fluid velocity $\left(\mathrm{V}, \mathrm{m} \mathrm{s}^{-1}\right)$, fluid density $\left(\rho, \mathrm{kg} \mathrm{m}^{-3}\right)$, and device efficiency $(\xi)$ :

$$
P D=\xi \frac{\rho}{2} V^{3}
$$

However, as hydrokinetic (HK) devices extract power from flowing water, they can alter the flow velocity, water elevation, sediment transport and other river properties and processes. The goal is to develop simple ways of estimating and representing the far-field hydraulic impacts of HK device deployments. In particular, we develop a technique for representing the presence of hydrokinetic devices with an enhanced bottom roughness. The enhanced bottom roughness can be used in standard hydraulic calculation procedures and models to determine the device impact.

A widely-used open channel flow equation for relating flow velocity (or discharge) to bottom roughness and channel properties is the Manning Equation. Here, the equation is presented in two forms: 


$$
V=\frac{1}{n} R^{2 / 3} S^{1 / 2} \text { or } Q=\frac{A}{n} R^{2 / 3} S^{1 / 2}
$$

where $\mathrm{V}$ is the cross-section averaged velocity $\left(\mathrm{m} \mathrm{s}^{-1}\right), \mathrm{n}$ is the Manning roughness coefficient $\left(\mathrm{m}^{-1 / 3} \mathrm{~s}\right), \mathrm{R}$ is the hydraulic radius (cross-sectional area/wetted perimeter, $\mathrm{m}), \mathrm{S}$ is the slope, $\mathrm{Q}$ is the discharge $\left(\mathrm{m}^{3} \mathrm{~s}^{-1}\right)$, and $\mathrm{A}\left(\mathrm{m}^{2}\right)$ is the cross-sectional area. Note, the second version of the Manning Equation is obtained from the first version through application of the continuity principle $(\mathrm{Q}=\mathrm{VA})$. Since $\mathrm{HK}$ devices tend to impede the flow of water, they can be represented with an enhanced bottom roughness, $\mathrm{n}_{\mathrm{t}}$. According to the Manning Equation, all other parameters being unchanged, an enhanced bottom roughness would cause a reduction in velocity. In a river setting, where the discharge can be considered constant, the reduced velocity will be compensated for with an increase in water depth.

The majority of previous work on the interaction of hydrokinetic devices and flowing water focused on the calculation of the available hydrokinetic power in tidal systems (Garrett and Cummins 2005, Bryden and Couch 2006, Sutherland et al. 2007, Garrett and Cummins 2008, Karsten et al. 2008, Polagye 2009). In tidal systems, often conceptualized as a channel connecting two basins - one semi-infinite and one finite - the central question is: what fraction of the total energy passing through the tidal channel is available for HK extraction? The researchers found that as the number of hydrokinetic devices increased, the flow rate of water through the channel decreased. Further, as the number of devices increased, there was a peak in total energy extraction followed by a decline.

Researchers (e.g., Garrett and Cummins 2007, Garrett and Cummins 2008) have also addressed the question of the relationship between the power extracted by hydrokinetic devices $\left(\mathrm{P}_{\text {extraction }}\right)$ and the total power dissipated by the presence of the devices $\left(\mathrm{P}_{\text {dissipation }}\right)$. The power extracted by hydrokinetic devices is the product of the power density (PD) and the swept area of the devices. Focusing on a single device in a channel, they noted that the devices generated a low velocity zone in their wake. Further, when the low water velocity wake mixed with the high velocity water that flowed around the device, significant energy was dissipated. Garrett and Cummins $(2007,2008)$ report:

$$
\frac{P_{\text {extraction }}}{P_{\text {dissipation }}}=\frac{2}{3(1+\varepsilon)}
$$

where is the blockage coefficient (i.e., the fraction of the river cross-sectional area occupied by the HK device). In this formulation, $\mathrm{P}_{\text {dissipation }}$ is the total power dissipated in a stretch of river. It is assumed that there are negligible drag losses.

\section{Analysis}

Here, we derive an expression for an enhanced or effective Manning roughness coefficient $\left(n_{t}\right)$ that can be used to represent the presence of hydrokinetic devices. The expression is obtained by considering the conservation of energy equation in two simple flow situations - Case A and Case B. Case A is a wide open channel flow situation in which the flow is steady and uniform. In Case B, hydrokinetic devices have been deployed such that they are distributed uniformly throughout the channel bottom. The channel in Case B is otherwise identical to the one in 
Case A. An expression for an enhanced Manning roughness that accounts for the presence of devices is readily determined by assuming that the total flow rate is the same in both situations.

\section{Representation of hydrokinetic devices with an enhanced bottom roughness}

Case A - uniform open channel flow with no hydrokinetic devices

Assuming flow from Location 1 to Location 2, the energy conservation equation (or modified Bernoulli Equation) for Case A (no devices) can be written (Munson et al. 2002):

$$
\frac{P_{1}}{\gamma}+\frac{V_{1}^{2}}{2 g}+z_{1}=\frac{P_{2}}{\gamma}+\frac{V_{2}^{2}}{2 g}+z_{2}+h_{L}
$$

where $\mathrm{P}_{1}$ and $\mathrm{P}_{2}$ are the pressures $(\mathrm{Pa})$ at locations 1 and 2, respectively, $\mathrm{V}_{1}$ and $\mathrm{V}_{2}$ are the velocities $\left(\mathrm{m} \mathrm{s}^{-1}\right)$ at locations 1 and 2, respectively, $z_{1}$ and $z_{2}$ are the elevations $(m)$ at locations 1 and 2, respectively, $\gamma$ is specific weight $\left(\mathrm{N} \mathrm{m}^{-3}\right)$, $\mathrm{g}$ is acceleration due to gravity $\left(9.8 \mathrm{~m} \mathrm{~s}^{-2}\right)$, and $\mathrm{h}_{\mathrm{L}}$ is head loss $(\mathrm{m})$ due to bottom friction.

Since flow is uniform in the direction of flow, the pressure and velocity terms cancel out and the energy equation can be written:

$$
z_{1}-z_{2}=\Delta z=h_{L}
$$

Further, recognizing that, for uniform flow, the bottom slope is the ratio of the head loss to the length of the channel section (i.e., $S=h_{L} / L$ ), Manning's Equation (Eq. B.2) can be rearranged to obtain head loss in terms of the flow rate, Manning's roughness, channel cross section area $\left(\mathrm{A}, \mathrm{m}^{2}\right)$, and hydraulic radius $(R, m)$ :

$$
h_{L}=\Delta z=\left(\frac{Q n}{A R^{\frac{2}{3}}}\right)^{2} \quad L
$$

Case B - uniform open channel flow with uniform distribution of hydrokinetic devices

In Case $\mathrm{B}$, the channel of Case $\mathrm{A}$ is altered to include hydrokinetic devices (i.e., turbines) that are distributed uniformly on the channel bottom. Water pressure $\left(\mathrm{P}_{1 \mathrm{t}}\right.$ and $\left.\mathrm{P}_{2 \mathrm{t}}\right)$ and flow velocity $\left(\mathrm{V}_{1 \mathrm{t}}\right.$ and $\left.\mathrm{V}_{2 \mathrm{t}}\right)$ differ from that seen in Case $\mathrm{A}$ due to the turbine presence. However, variables such as discharge, channel width, and bottom slope remain the same. The energy conservation equation for Case B has the following form: 


$$
\frac{P_{1 \mathrm{t}}}{\gamma}+\frac{V_{1 \mathrm{t}}^{2}}{2 g}+z_{1}=\frac{P_{2 \mathrm{t}}}{\gamma}+\frac{V_{2 \mathrm{t}}^{2}}{2 g}+z_{2}+h_{L t}+h_{p}
$$

where $h_{L t}$ is the head loss due to the bottom friction (i.e., contact of the flowing water with the "natural" channel bottom) and $h_{p}$ is the "head loss" associated with the presence of the hydrokinetic devices (described below).

Since the turbines are uniformly distributed, flow conditions continue to be uniform in the direction of flow. Consequently, upstream and downstream velocity and pressure heads are the same and Equation B.7 can be simplified to:

$$
z_{1}-z_{2}=\Delta z=h_{L t}+h_{p}
$$

Using the same approach as for Equation B.5, the head loss associated with bottom friction can be expressed:

$$
h_{L t}=\left(\frac{Q n}{A_{t} R_{t}^{\frac{2}{3}}}\right)^{2} L
$$

where $A_{t}$ and $R_{t}$ are the cross-sectional area and hydraulic radius of the channel when turbines are present. Since the channel geometry in the two cases is the same, Equation B.8 can be written using Equations B.7 and B.9 obtaining:

$$
\left(\frac{Q n}{A R^{\frac{2}{3}}}\right)^{2} L=\left(\frac{Q n}{A_{t} R^{\frac{2}{3}}}\right)^{2} L+h_{p}
$$

Assuming a very wide rectangular channel such that the hydraulic radius is the water depth and the cross-sectional area is the product of the width and depth, Equation B.10 becomes:

$\left(\frac{Q n}{w h^{\frac{5}{3}}}\right)^{2} L=\left(\frac{Q n}{w h^{\frac{5}{3}}}\right)^{2} L+h_{p}$

where $h_{t}$ is the water depth with devices present.

\section{Channel energy losses due to presence of hydrokinetic devices}

Assuming drag losses to be negligible (following Polagye (2009)), the total power dissipated can be estimated based on the blockage area and extracted power as described in Equation B.3. The total power dissipation can be expressed as a "head loss" (i.e., as $\mathrm{h}_{\mathrm{p}}$ ) by dividing by the product of discharge and the specific weight (i.e., $\gamma \mathrm{Q})$ obtaining:

$$
h_{p}=\frac{\mathrm{P}_{\text {dissipation }}}{\gamma \mathrm{Q}}=\frac{3}{4} \frac{\rho N A_{r} \mathrm{~V}_{\mathrm{t}}^{3}}{\gamma \mathrm{Q}}(\xi(1+\epsilon))=\left(\frac{3}{4} \frac{N A_{r} Q^{2}}{g w^{3}} \cdot \xi(1+\epsilon)\right) \cdot \frac{1}{h_{t}{ }^{3}}
$$

Eq. $\quad B-12$ 
where $\mathrm{N}$ is the number of hydrokinetic devices in the channel segment,

$\mathrm{A}_{\mathrm{r}}$ is the swept area of an individual hydrokinetic device $\left(\mathrm{m}^{2}\right)$,

$V_{t}$ is the cross-section averaged velocity with devices present $\left(\mathrm{m} \mathrm{s}^{-1}\right)$,

$\mathrm{w}$ is the channel width (m), and

$h_{t}$ is the channel depth with devices present $\left(\mathrm{m}^{2}\right)$.

\section{Determination of water depth with devices present}

Using the expression for "head loss" due to the presence of hydrokinetic devices (Equation B.12), Equation B.11 can be rearranged obtaining:

$$
h^{-10 / 3}-h_{t}^{-10 / 3}-\left(\frac{3}{4} \frac{\xi(1+\epsilon)}{n^{2} g} \cdot \frac{N A_{r}}{w L}\right) \cdot h_{t}^{-3}=0
$$

From Equation B.13, it is apparent that the increased depth associated with the deployment of hydrokinetic devices $\left(h_{t}\right)$ can be determined from the character of the channel and the character and number of the devices. Through the principle of continuity, the cross-section averaged velocity can also be determined.

Equation B.13 was rearranged obtaining:

$$
x^{3}-x^{-\frac{1}{3}}-a=0
$$

where $\mathrm{x}=\frac{h_{t}}{h}$ and $\mathrm{a}=\left(\frac{3}{4} \frac{\xi(1+\epsilon)}{n^{2} g} \cdot \frac{N A_{r}}{w L}\right) \cdot h^{1 / 3}$.

Next, Equation B.14 was approximated by a cubic polynomial (using MATLAB):

$$
1.0849 \cdot x^{3}-0.45336 \cdot x^{2}+0.98303 \cdot x-1.6145-\mathrm{a}=0 \quad \text { Eq. B-15 }
$$

The cubic polynomial was solved (for $\mathrm{x}$ ) and the solution was used to determine the following relationship between $b_{t}, b$, and $a$ :

$$
h_{t}=h \cdot\left(b^{1 / 3}-0.28263 \cdot b^{-1 / 3}+0.139296\right) \quad \text { Eq. B-16 }
$$

where:

$$
b=0.46088 \cdot a+\left((0.46088 \cdot a+0.68368)^{2}+0.022578\right)^{1 / 2}+0.68368
$$

For values of $\mathrm{x}$ ranging from 1 to 1.5 , and for $a$ ranging from 0 to 2.50142 , the cubic polynomial approximation was found to generate estimates of $\mathrm{x}$ ( or $\frac{h_{t}}{h}$ ) that were very accurate (within $10^{-3}$ percent). Equation B.16 demonstrates that the hydraulic impacts of a uniform distribution of hydrokinetic devices can be estimated based on a single parameter (parameter $a$, Eq. B.14). 


\section{Determination of the effective Manning's roughness coefficient and velocity with devices present}

Having determined $b_{t} / h$ as a function of parameter $a$, the enhanced Manning roughness coefficient representing the presence of the hydrokinetic devices (i.e., turbines) can be readily determined. Since the discharge and slope under Case A and $\mathrm{B}$ are the same, the Manning Equation (Equation 2) can be used to establish a relationship between $h, h_{t}, n$, and $n_{t}$ :

$$
\frac{w h}{n} h^{\frac{2}{3}}=\frac{w h_{t}}{n_{t}}\left(h_{t}\right)^{\frac{2}{3}}
$$

Solving for $\mathrm{n}_{\mathrm{t}}$, we have:

$$
n_{t}=\left(\frac{h_{t}}{h}\right)^{5 / 3} \cdot n
$$

Based on the continuity principle, the velocity with devices present $\left(V_{t} \mathrm{~m} \mathrm{~s}^{-1}\right)$ can also be determined based on $h_{t} / h$ or $n_{t} / n$ :

$$
V_{t}=\left(\frac{h}{h_{t}}\right) V=\left(\frac{n}{n_{t}}\right)^{3 / 5} V
$$

\section{Example calculation of the hydraulic impact of a uniform distribution of hydrokinetic devices}

In order to illustrate the technique for estimating the hydraulic impact of hydrokinetic devices, a set of channel, flow, and hydrokinetic device properties were assumed (Table B.1). Further, it was assumed that the hydrokinetic devices were deployed in rows (normal to the flow) separated by 10 device diameters (i.e., $10 \mathrm{D}$ or $80 \mathrm{~m}$ ). Given the properties in Table B.1, it is clear that we were modeling a single row of devices with the roughness of the devices distributed throughout the channel length. Then, assuming an increasing number of devices per row (or number of devices in the $80 \mathrm{~m}$ long channel segment), the impact of the devices on the normalized depth $\left(b_{t} / h\right)$, normalized effective bottom roughness $\left(n_{\mathrm{t}} / n\right)$, and normalized velocity $\left(V_{\mathrm{t}} / V\right)$ were calculated based on Equations B.16, B.18, and B.19, respectively as a function of the number of devices per row (or per $10 \mathrm{D}$ of channel length). (Figure B.1). In this example, the maximum number of devices per row was capped at 20 . This amounts to spacing between devices of $17.9 \mathrm{~m}$ or $2.2 \mathrm{D}$. This spacing is approximately equal to $2 \mathrm{D}$, which is often considered an upper density limit. 
Table B-1

Channel, flow, and turbine properties assumed in example calculation.

\begin{tabular}{|l|c|c|}
\hline \multicolumn{1}{|c|}{ Variable } & Symbol & Value \\
\hline water depth & $\mathrm{h}$ & $10 \mathrm{~m}$ \\
\hline channel width & $\mathrm{w}$ & $500 \mathrm{~m}$ \\
\hline channel length & $\mathrm{L}$ & $80 \mathrm{~m}$ \\
\hline Slope & $\mathrm{S}$ & 0.0002 \\
\hline Manning roughness & $\mathrm{n}$ & 0.025 \\
\hline turbine efficiency & $\xi$ & $32 \%$ \\
\hline turbine swept area & $\mathrm{A}_{\mathrm{r}}$ & $51 \mathrm{~m}^{2}$ \\
\hline
\end{tabular}

Figure B.1 also shows the blockage ratio $(\epsilon)$, power density, and total power (for a $80 \mathrm{~m}$ long channel) as a function of density of hydrokinetic devices (i.e., number of devices per row). It is noteworthy that the normalized depth, Manning roughness, and velocity all start at a value of 1.0 on the left side of the plot (where the device density is 0 ). As the density of devices increases, the normalized depth and Manning roughness monotonically increase whereas the normalized velocity decreases. Initially, the total extracted power increases rapidly. Later, there are diminishing returns in extracted power with incremental increases of device density. This is because the water has been slowed by the devices that have already been deployed in the channel. The diminishing energy level of the channel with increasing device density is shown by the power density curve which decreases rapidly with increasing numbers of devices.

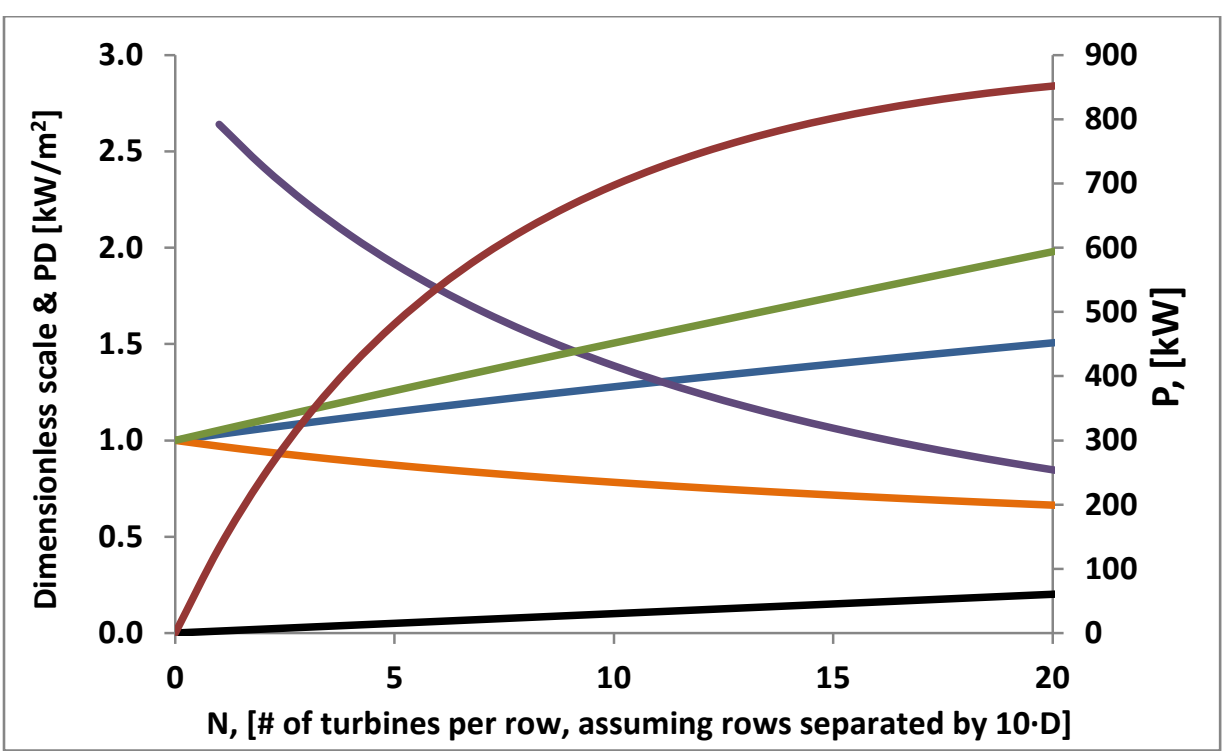

Figure B-1

Plot of normalized depth $(h / h-1)$, normalized velocity $(V, / V=)$, normalized effective Manning roughness $\left(n_{t} / n=\right)$, power density (PD, $\left.k W m^{-2}=\right)$, extracted power in a 500-m long channel section ( $P, k W=)$, and blockage ratio ( )as a function of density of hydrokinetic devices (number of devices per $10 \mathrm{D}$ m length). 
The blockage ratio plotted in Figure B.1 and used in equation B.14 is based on the water depth in a device-free channel (h). That is, the calculations of blockage ratio presented here do not account for the depth increase due to the presence of HK devices. Calculations show that including these "back effects" in the blockage ratio has a negligible effect on water level. For example, for the situation shown in Figure B.1, if the back effect is accounted for the $h_{t} / h$ ratio at 20 devices per row would decrease from 1.506 to 1.486 , $\square$ change $598 \mathrm{z}$.

\section{Hydraulic impacts of HK devices associated with deployments in spatially limited areas}

The previous section indicated that a uniform distribution of hydrokinetic devices can have a significant impact on water level and velocity. In order to determine the impact of hydrokinetic devices when they are deployed in limited areas, a 1D numerical model (ISIS) was employed. To illustrate the impact of different spatial extents of hydrokinetic device deployments, a single device density (27 devices per $500 \mathrm{~m}$ segment or 4.5 per $80 \mathrm{~m}$ segment) and the same channel geometry was assumed (Table B.2). However, the longitudinal extent of the deployment was limited to just $500 \mathrm{~m}$ (Figure B.2). In this case the water level and velocity impact was significantly reduced relative to the impacts obtained if the device deployment was unlimited in the longitudinal direction (Figure B.3). Specifically, the enhancement in water level was only about $6 \mathrm{~cm}$ instead of about $1.1 \mathrm{~m}$.

Table B-2

Channel, flow and turbine properties assumed.

\begin{tabular}{|l|c|c|}
\hline \multicolumn{1}{|c|}{ Variable } & Symbol & Value \\
\hline water depth & $\mathrm{h}$ & $10 \mathrm{~m}$ \\
\hline channel width & $\mathrm{w}$ & $500 \mathrm{~m}$ \\
\hline Slope & $\mathrm{S}$ & 0.0002 \\
\hline Manning roughness (no devices) & $\mathrm{n}$ & 0.025 \\
\hline turbine efficiency & $\xi$ & $32 \%$ \\
\hline turbine swept area & $\mathrm{A}_{\mathrm{r}}$ & $51 \mathrm{~m}^{2}$ \\
\hline Manning roughness & $\mathrm{n}_{\mathrm{t}}$ & 0.0308 \\
\hline (18 devices per 100 m Segment) & & \\
\hline
\end{tabular}




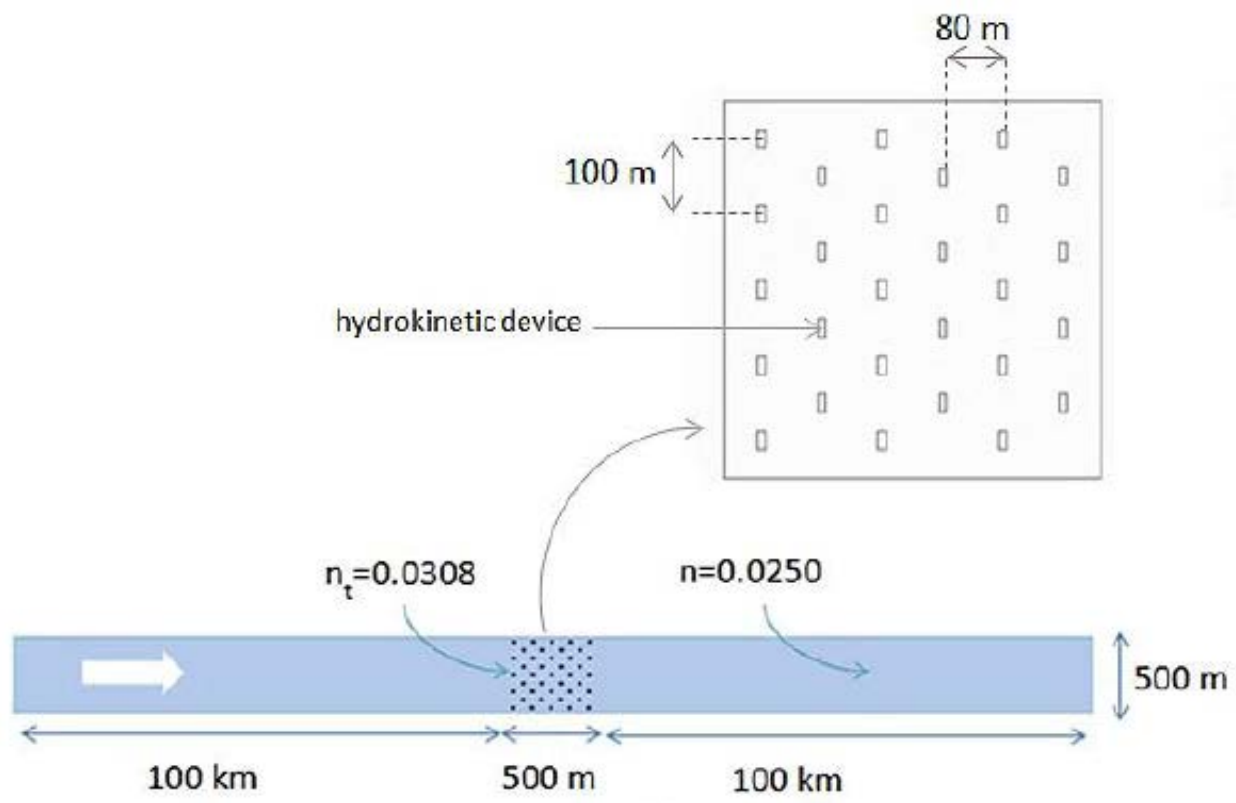

Figure B-2

Cartoon illustrating the spatially limited deployment of hydrokinetic devices. 

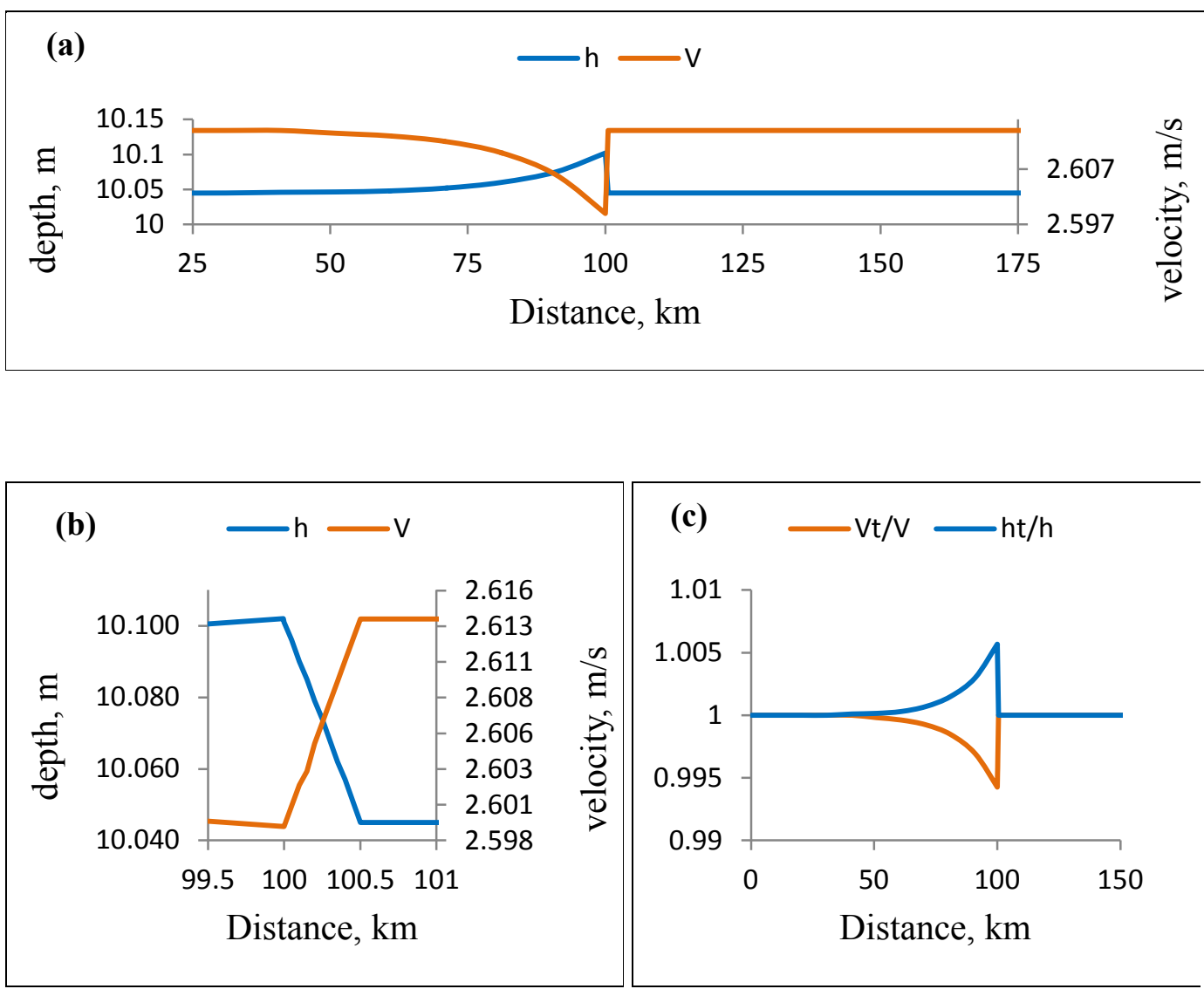

Figure B-3

Hydraulic impact of a spatially-limited deployment of hydrokinetic devices including (a) velocity and water depth within $75 \mathrm{~km}$ of the hydrokinetic devices; (b) Velocity and water depth within $0.5 \mathrm{~km}$ of the devices; and (c) normalized velocity and normalized depth proximal to the devices. 


\section{Notation}

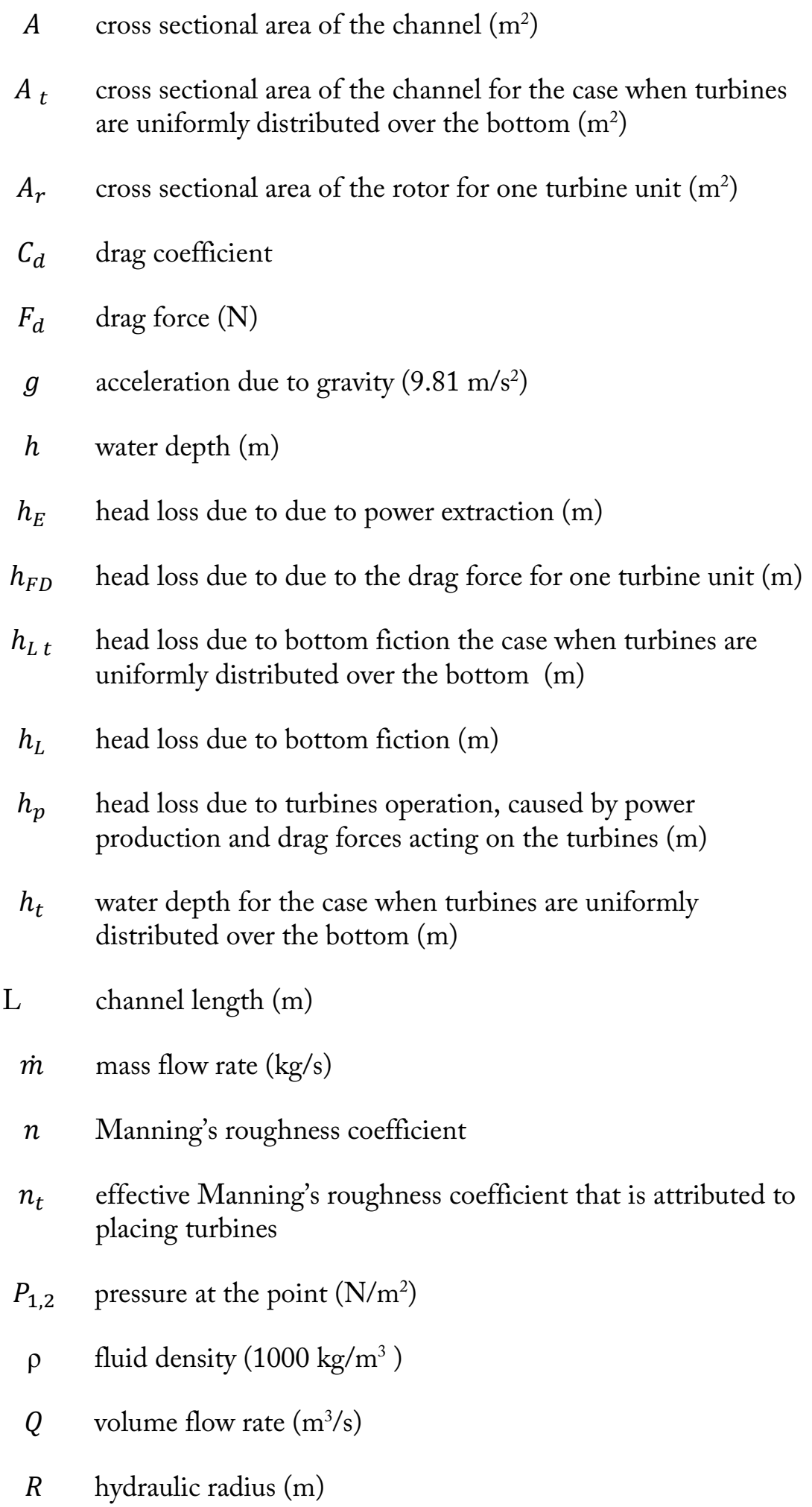




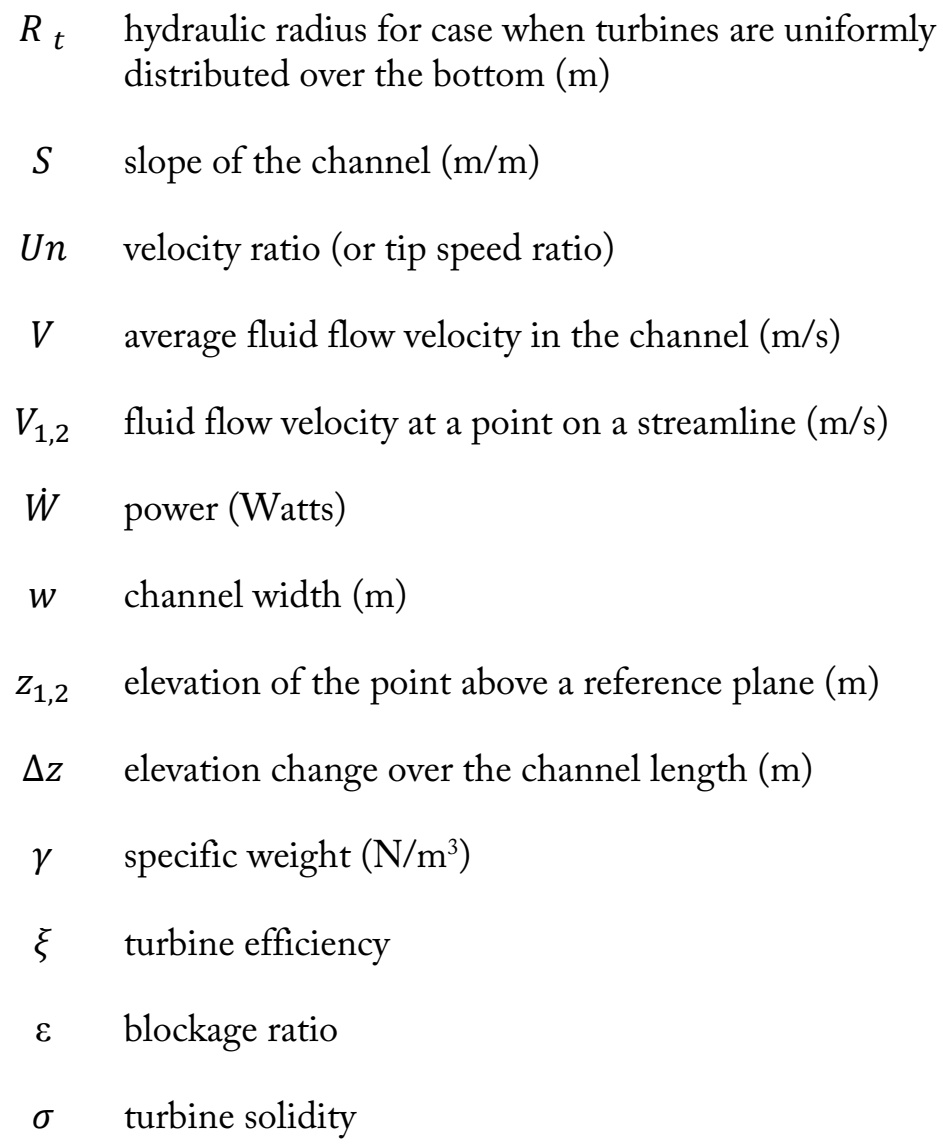




\section{Appendix C: Theoretical and Technically Recoverable Riverine Hydrokinetic Power in Alaska}

The theoretical resource was estimated for the segments of major Alaska rivers with average discharge greater than 10,000 cfs. These river segments and their associated theoretical power are listed in Table C-1. 
Table C-1

Theoretical in-stream hydrokinetic power in segments of the major Alaska rivers in which the annual average flow rate exceeds $10,000 \mathrm{cfs}\left(283 \mathrm{~m}^{3} / \mathrm{s}\right)$.

\begin{tabular}{|c|c|c|c|c|c|c|}
\hline River & Segment start & Segment end & $\begin{array}{c}Q_{\text {ave }} \\
\left(\mathrm{m}^{3} / \mathrm{s}\right)\end{array}$ & $\begin{array}{l}\Delta H \\
\text { (m) }\end{array}$ & $\begin{array}{l}\text { Power } \\
\text { (MW) }\end{array}$ & $\begin{array}{l}\text { Power } \\
\text { (TWh/yr) }\end{array}$ \\
\hline \multirow[t]{5}{*}{ Yukon } & Kaltag & Pilot Station & 6284 & 30.2 & 1858.8 & 16.3 \\
\hline & Ruby & Kaltag & 5413 & 13.1 & 695.4 & 6.1 \\
\hline & Stevens Village & Ruby & 4031 & 47.9 & 1891.0 & 16.6 \\
\hline & Eagle & Stevens Village & 2876 & 168.3 & 4743.9 & 41.6 \\
\hline & & & & & TOTAL: & 80.5 \\
\hline \multirow[t]{4}{*}{ Koyukuk } & Hughes & Koyukuk & 575 & 50.0 & 281.9 & 2.5 \\
\hline & $66^{\circ} 34^{\prime} \mathrm{N}, 152^{\circ} 38^{\prime} \mathrm{W}$ & Hughes & 408 & 30.8 & 123.1 & 1.1 \\
\hline & $66^{\circ} 49^{\prime} \mathrm{N}, 151^{\circ} 47^{\prime} \mathrm{W}$ & $66^{\circ} 34^{\prime} \mathrm{N}, 152^{\circ} 38^{\prime} \mathrm{W}$ & 282 & 43.9 & 121.3 & 1.1 \\
\hline & & & & & TOTAL: & 4.6 \\
\hline \multirow[t]{4}{*}{ Tanana } & Fairbanks & Nenana & 621 & 28.4 & 172.4 & 1.5 \\
\hline & Big Delta & Fairbanks & 485 & 163.7 & 777.5 & 6.8 \\
\hline & Tok Junction & Big Delta & 300 & 452.4 & 1331.9 & 11.7 \\
\hline & & & & & TOTAL: & 20.0 \\
\hline \multirow[t]{7}{*}{ Kuskokwim } & Chuathbaluk & Bethel & 1773 & 26.8 & 466.2 & 4.1 \\
\hline & Crooked Creek & Chuathbaluk & 1415 & 14.3 & 198.7 & 1.7 \\
\hline & Stony River & Crooked Creek & 1120 & 19.8 & 217.5 & 1.9 \\
\hline & $62^{\circ} 23^{\prime} \mathrm{N}, 156^{\circ} \mathrm{O}^{\prime} \mathrm{W}$ & Stony River & 854 & 23.2 & 193.8 & 1.7 \\
\hline & $62^{\circ} 47^{\prime} \mathrm{N}, 155^{\circ} 45^{\prime} \mathrm{W}$ & $62^{\circ} 23^{\prime} \mathrm{N}, 156^{\circ} \mathrm{O}^{\prime} \mathrm{W}$ & 632 & 14.9 & 92.5 & 0.8 \\
\hline & $63^{\circ} 0^{\prime} \mathrm{N}, 154^{\circ} 54^{\prime} \mathrm{W}$ & $62^{\circ} 47^{\prime} \mathrm{N}, 155^{\circ} 45^{\prime} \mathrm{W}$ & 446 & 7.9 & 34.7 & 0.3 \\
\hline & & & & & TOTAL: & 10.5 \\
\hline
\end{tabular}


Table C-1 (continued)

Theoretical in-stream hydrokinetic power in segments of the major Alaska rivers in which the annual average flow rate exceeds $10,000 \mathrm{cfs}\left(283 \mathrm{~m}^{3} / \mathrm{s}\right)$.

\begin{tabular}{|c|c|c|c|c|c|c|}
\hline River & Segment start & Segment end & $\begin{array}{c}Q_{\text {ave }} \\
\left(\mathrm{m}^{3} / \mathrm{s}\right)\end{array}$ & $\begin{array}{l}\Delta H \\
(\mathrm{~m})\end{array}$ & $\begin{array}{l}\text { Power } \\
\text { (MW) }\end{array}$ & $\begin{array}{l}\text { Power } \\
\text { (TWh/yr) }\end{array}$ \\
\hline \multirow[t]{4}{*}{ Stikine } & $56^{\circ} 40^{\prime} \mathrm{N}, 132^{\circ} 7^{\prime} \mathrm{W}$ & Coast & 3863 & 0.8 & 31.2 & 0.3 \\
\hline & $56^{\circ} 42^{\prime} \mathrm{N}, 132^{\circ} \mathrm{O}^{\prime} \mathrm{W}$ & $56^{\circ} 40^{\prime} \mathrm{N}, 132^{\circ} 7^{\prime} \mathrm{W}$ & 3843 & 2.5 & 93.0 & 0.8 \\
\hline & $56^{\circ} 93^{\prime} \mathrm{N}, 131^{\circ} 51^{\prime} \mathrm{W}$ & $56^{\circ} 42^{\prime} \mathrm{N}, 132^{\circ} \mathrm{O}^{\prime} \mathrm{W}$ & 3816 & 3.7 & 139.1 & 1.2 \\
\hline & & & & & TOTAL: & 2.3 \\
\hline \multirow[t]{4}{*}{ Kvichak } & $59^{\circ} 12^{\prime} \mathrm{N}, 156^{\circ} 26^{\prime} \mathrm{W}$ & Coast & 738 & 10.1 & 72.8 & 0.6 \\
\hline & $59^{\circ} 15^{\prime} \mathrm{N}, 156^{\circ} 5^{\prime} \mathrm{W}$ & $59^{\circ} 12^{\prime} \mathrm{N}, 156^{\circ} 26^{\prime} \mathrm{W}$ & 723 & 3.7 & 25.9 & 0.2 \\
\hline & $59^{\circ} 20^{\prime} \mathrm{N}, 155^{\circ} 54^{\prime} \mathrm{W}$ & $59^{\circ} 15^{\prime} \mathrm{N}, 156^{\circ} 5^{\prime} \mathrm{W}$ & 699 & 1.6 & 10.6 & 0.1 \\
\hline & & & & & TOTAL: & 0.9 \\
\hline \multirow[t]{7}{*}{ Nushagak } & $58^{\circ} 52^{\prime} \mathrm{N}, 157^{\circ} 50^{\prime} \mathrm{W}$ & Coast & 827 & 3.1 & 25.0 & 0.2 \\
\hline & $59^{\circ} 2^{\prime} \mathrm{N}, 157^{\circ} 46^{\prime} \mathrm{W}$ & $58^{\circ} 52^{\prime} \mathrm{N}, 157^{\circ} 50^{\prime} \mathrm{W}$ & 823 & 5.5 & 44.5 & 0.4 \\
\hline & $59^{\circ} 18^{\prime} \mathrm{N}, 157^{\circ} 34^{\prime} \mathrm{W}$ & $59^{\circ} 2^{\prime} \mathrm{N}, 157^{\circ} 46^{\prime} \mathrm{W}$ & 772 & 6.9 & 52.5 & 0.5 \\
\hline & $59^{\circ} 25^{\prime} \mathrm{N}, 157^{\circ} 19^{\prime} \mathrm{W}$ & $59^{\circ} 18^{\prime} \mathrm{N}, 157^{\circ} 34^{\prime} \mathrm{W}$ & 714 & 14.5 & 101.2 & 0.9 \\
\hline & $59^{\circ} 32^{\prime} \mathrm{N}, 157^{\circ} 5^{\prime} \mathrm{W}$ & $59^{\circ} 25^{\prime} \mathrm{N}, 157^{\circ} 19^{\prime} \mathrm{W}$ & 696 & 9.8 & 66.9 & 0.6 \\
\hline & $59^{\circ} 48^{\prime} \mathrm{N}, 156^{\circ} 48^{\prime} \mathrm{W}$ & $59^{\circ} 37^{\prime} \mathrm{N}, 15^{\circ} 76^{\prime} \mathrm{W}$ & 296 & 33.0 & 95.9 & 0.8 \\
\hline & & & & & TOTAL: & 3.4 \\
\hline \multirow[t]{4}{*}{ Susitna } & Sunshine & Cook Inlet & 862 & 77.7 & 657.0 & 5.8 \\
\hline & $62^{\circ} 17^{\prime} \mathrm{N}, 150^{\circ} 8^{\prime} \mathrm{W}$ & Sunshine & 555 & 16.8 & 91.2 & 0.8 \\
\hline & $62^{\circ} 24,150^{\circ} 10^{\prime} \mathrm{W}$ & $62^{\circ} 17,150^{\circ} 8^{\prime} \mathrm{W}$ & 343 & 13.1 & 44.1 & 0.4 \\
\hline & & & & & TOTAL: & 6.9 \\
\hline
\end{tabular}


Table C-1 (continued)

Theoretical in-stream hydrokinetic power in segments of the major Alaska rivers in which the annual average flow rate exceeds $10,000 \mathrm{cfs}\left(283 \mathrm{~m}^{3} / \mathrm{s}\right)$.

\begin{tabular}{|c|c|c|c|c|c|c|}
\hline River & Segment start & Segment end & $\begin{array}{c}Q_{\text {ave }} \\
\left(\mathrm{m}^{3} / \mathrm{s}\right)\end{array}$ & $\begin{array}{l}\Delta H \\
(\mathbf{m})\end{array}$ & $\begin{array}{l}\text { Power } \\
\text { (MW) }\end{array}$ & $\begin{array}{l}\text { Power } \\
\text { (TWh/yr) }\end{array}$ \\
\hline \multirow[t]{2}{*}{ Porcupine } & $67^{\circ} 25^{\prime} \mathrm{N}, 141^{\circ} 1^{\prime} \mathrm{N}$ & $66^{\circ} 35^{\prime} \mathrm{N}, 145^{\circ} 21^{\prime} \mathrm{N}$ & 454 & 83.2 & 370.4 & 3.2 \\
\hline & & & & & TOTAL: & 3.2 \\
\hline \multirow[t]{4}{*}{ Colville } & $69^{\circ} 54^{\prime} \mathrm{N}, 151^{\circ} 29^{\prime} \mathrm{W}$ & Coast & 319 & 14.9 & 46.7 & 0.4 \\
\hline & Umiat & $69^{\circ} 54^{\prime} \mathrm{N}, 151^{\circ} 29^{\prime} \mathrm{W}$ & 295 & 69.5 & 200.9 & 1.8 \\
\hline & $65^{\circ} 9^{\prime} \mathrm{N}, 154^{\circ} 24^{\prime} \mathrm{W}$ & Umiat & 218 & 105.5 & 225.0 & 2.0 \\
\hline & & & & & TOTAL: & 4.1 \\
\hline \multirow[t]{3}{*}{ Noatak } & $67^{\circ} 8^{\prime} \mathrm{N}, 162^{\circ} 36^{\prime} \mathrm{W}$ & Coast & 312 & 4.0 & 12.2 & 0.1 \\
\hline & $67^{\circ} 17^{\prime} \mathrm{N}, 162^{\circ} 40^{\prime} \mathrm{W}$ & $67^{\circ} 8^{\prime} \mathrm{N}, 162^{\circ} 36^{\prime} \mathrm{W}$ & 306 & 0.8 & 2.3 & 0.0 \\
\hline & & & & & TOTAL: & 0.1 \\
\hline \multirow[t]{12}{*}{ Copper } & $60^{\circ} 43^{\prime} \mathrm{N}, 144^{\circ} 39^{\prime} \mathrm{W}$ & Coast & 1666 & 38.1 & 622.3 & 5.5 \\
\hline & $60^{\circ} 49^{\prime} \mathrm{N}, 144^{\circ} 31^{\prime} \mathrm{W}$ & $60^{\circ} 43^{\prime} \mathrm{N}, 144^{\circ} 39^{\prime} \mathrm{W}$ & 1574 & 14.9 & 230.5 & 2.0 \\
\hline & $61^{\circ} 1^{\prime} \mathrm{N}, 144^{\circ} 48^{\prime} \mathrm{W}$ & $60^{\circ} 49^{\prime} \mathrm{N}, 144^{\circ} 31^{\prime} \mathrm{W}$ & 1462 & 20.1 & 288.4 & 2.5 \\
\hline & $61^{\circ} 15^{\prime} \mathrm{N}, 144^{\circ} 53^{\prime} \mathrm{W}$ & $61^{\circ} 1^{\prime} \mathrm{N}, 144^{\circ} 48^{\prime} \mathrm{W}$ & 1380 & 11.0 & 148.4 & 1.3 \\
\hline & $61^{\circ} 25^{\prime} \mathrm{N}, 144^{\circ} 39^{\prime} \mathrm{W}$ & $61^{\circ} 15^{\prime} \mathrm{N}, 144^{\circ} 53^{\prime} \mathrm{W}$ & 1313 & 22.9 & 294.3 & 2.6 \\
\hline & $61^{\circ} 28^{\prime} \mathrm{N}, 144^{\circ} 26^{\prime} \mathrm{W}$ & $61^{\circ} 25^{\prime} \mathrm{N}, 144^{\circ} 39^{\prime} \mathrm{W}$ & 1306 & 29.9 & 382.5 & 3.4 \\
\hline & $61^{\circ} 31^{\prime} \mathrm{N}, 144^{\circ} 21^{\prime} \mathrm{W}$ & $61^{\circ} 28^{\prime} \mathrm{N}, 144^{\circ} 26^{\prime} \mathrm{W}$ & 822 & 9.5 & 76.1 & 0.7 \\
\hline & $61^{\circ} 31^{\prime} \mathrm{N}, 144^{\circ} 18^{\prime} \mathrm{W}$ & $61^{\circ} 31^{\prime} \mathrm{N}, 144^{\circ} 21^{\prime} \mathrm{W}$ & 818 & 5.8 & 46.4 & 0.4 \\
\hline & $61^{\circ} 27^{\prime} \mathrm{N}, 144^{\circ} 9^{\prime} \mathrm{W}$ & $61^{\circ} 31^{\prime} \mathrm{N}, 144^{\circ} 18^{\prime} \mathrm{W}$ & 806 & 15.9 & 125.3 & 1.1 \\
\hline & $61^{\circ} 23^{\prime} \mathrm{N}, 144^{\circ} 5^{\prime} \mathrm{W}$ & $61^{\circ} 27^{\prime} \mathrm{N}, 144^{\circ} 9^{\prime} \mathrm{W}$ & 798 & 14.9 & 116.8 & 1.0 \\
\hline & $61^{\circ} 20^{\prime} \mathrm{N}, 143^{\circ} 25^{\prime} \mathrm{W}$ & $61^{\circ} 23^{\prime} \mathrm{N}, 144^{\circ} 5^{\prime} \mathrm{W}$ & 778 & 61.0 & 464.8 & 4.1 \\
\hline & $61^{\circ} 11^{\prime} \mathrm{N}, 142^{\circ} 48^{\prime} \mathrm{W}$ & $61^{\circ} 20^{\prime} \mathrm{N}, 143^{\circ} 25^{\prime} \mathrm{W}$ & 707 & 84.1 & 583.1 & 5.1 \\
\hline
\end{tabular}


Table C-1 (continued)

Theoretical in-stream hydrokinetic power in segments of the major Alaska rivers in which the annual average flow rate exceeds $10,000 \mathrm{cfs}\left(283 \mathrm{~m}^{3} / \mathrm{s}\right)$.

\begin{tabular}{|c|c|c|c|c|c|c|}
\hline River & Segment start & Segment end & $\begin{array}{c}Q_{\text {ave }} \\
\left(\mathrm{m}^{3} / \mathrm{s}\right)\end{array}$ & $\begin{array}{l}\Delta H \\
(\mathbf{m})\end{array}$ & $\begin{array}{l}\text { Power } \\
\text { (MW) }\end{array}$ & $\begin{array}{l}\text { Power } \\
\text { (TWh/yr) }\end{array}$ \\
\hline \multirow[t]{11}{*}{ Copper } & $61^{\circ} 4^{\prime} \mathrm{N}, 142^{\circ} 50^{\prime} \mathrm{W}$ & $61^{\circ} 11^{\prime} \mathrm{N}, 142^{\circ} 52^{\prime} \mathrm{W}$ & 303 & 37.8 & 112.3 & 1.0 \\
\hline & $61^{\circ} 0^{\prime} \mathrm{N}, 142^{\circ} 43^{\prime} \mathrm{W}$ & $61^{\circ} 4^{\prime} \mathrm{N}, 142^{\circ} 50^{\prime} \mathrm{W}$ & 302 & 32.3 & 95.6 & 0.8 \\
\hline & $60^{\circ} 57^{\prime} \mathrm{N}, 142^{\circ} 40^{\prime} \mathrm{W}$ & $61^{\circ} \mathrm{O}^{\prime} \mathrm{N}, 142^{\circ} 43^{\prime} \mathrm{W}$ & 300 & 12.8 & 37.7 & 0.3 \\
\hline & $61^{\circ} 38^{\prime} \mathrm{N}, 144^{\circ} 35^{\prime} \mathrm{W}$ & $61^{\circ} 30^{\prime} \mathrm{N}, 144^{\circ} 24^{\prime} \mathrm{W}$ & 521 & 22.0 & 112.2 & 1.0 \\
\hline & $61^{\circ} 41^{\prime} \mathrm{N}, 144^{\circ} 40^{\prime} \mathrm{W}$ & $61^{\circ} 38^{\prime} \mathrm{N}, 144^{\circ} 35^{\prime} \mathrm{W}$ & 490 & 22.9 & 109.9 & 1.0 \\
\hline & $61^{\circ} 44^{\prime} \mathrm{N}, 144^{\circ} 48^{\prime} \mathrm{W}$ & $61^{\circ} 41^{\prime} \mathrm{N}, 144^{\circ} 40^{\prime} \mathrm{W}$ & 465 & 16.2 & 73.7 & 0.6 \\
\hline & $61^{\circ} 50^{\prime} \mathrm{N}, 145^{\circ} 10^{\prime} \mathrm{W}$ & $61^{\circ} 44^{\prime} \mathrm{N}, 144^{\circ} 48^{\prime} \mathrm{W}$ & 453 & 60.7 & 269.1 & 2.4 \\
\hline & $61^{\circ} 56^{\prime} \mathrm{N}, 145^{\circ} 20^{\prime} \mathrm{W}$ & $61^{\circ} 50^{\prime} \mathrm{N}, 145^{\circ} 10^{\prime} \mathrm{W}$ & 446 & 23.2 & 101.4 & 0.9 \\
\hline & $62^{\circ} 3^{\prime} \mathrm{N}, 145^{\circ} 21^{\prime} \mathrm{W}$ & $61^{\circ} 56^{\prime} \mathrm{N}, 145^{\circ} 20^{\prime} \mathrm{W}$ & 421 & 34.1 & 140.8 & 1.2 \\
\hline & $62^{\circ} 8^{\prime} \mathrm{N}, 145^{\circ} 26^{\prime} \mathrm{W}$ & $62^{\circ} 3^{\prime} \mathrm{N}, 145^{\circ} 21^{\prime} \mathrm{W}$ & 344 & 24.7 & 83.3 & 0.7 \\
\hline & & & & & TOTAL: & 39.6 \\
\hline
\end{tabular}


The technically recoverable hydrokinetic resource for the selected Alaska river segments with average discharge greater than 10,000 cfs is presented in Table C-2.

Table C-2

Technically recoverable hydrokinetic resource (TWh/yr) in portions of selected Alaska rivers with average discharge greater than 10,000 cfs.

\begin{tabular}{|c|c|}
\hline River & $\begin{array}{c}\text { Technically Recoverable } \\
\text { Resource (TWh/yr) }\end{array}$ \\
\hline Yukon & 13.2 \\
\hline Koyukuk & 0.2 \\
\hline Tanana & 0.7 \\
\hline Kuskokwim & 1.1 \\
\hline Stikine & 0.4 \\
\hline Kvichak & 0.1 \\
\hline Nushagak & 0.2 \\
\hline Susitna & 0.5 \\
\hline Porcupine & 0.1 \\
\hline Colville & 0.1 \\
\hline Noatak & 0.003 \\
\hline Copper & 3.3 \\
\hline Total & 19.9 \\
\hline
\end{tabular}

In $\square[3$ \# ( 3 the theoretical resource in Alaska was estimated to $59 \mathrm{TWh} / \mathrm{yr}$ in rivers with annual flow rates between 10,000 and 1,000 cfs. Examination of the dependence of recovery factor on discharge (Eq. 4.4) indicates that there would only be a positive recovery factor for flows greater than 7,000 cfs. In order to obtain an upper bound on an estimate of the technically recoverable resource in Alaska for flows between 10,000 and 1,000 cfs, we calculated the recovery factor (RF) based on a flow rate of 8,500 cfs (mid-point between 7,000 and 10,000 cfs), finding $\mathrm{RF}=0.011$. The Alaska technically recoverable resource for flows between 10,000 and 1,000 cfs was then estimated to be $0.6 \mathrm{TWh} / \mathrm{yr}$ for these low flow rivers. This brought the total technically recoverable in-stream hydrokinetic power in Alaska to $20.5 \mathrm{TWh} / \mathrm{yr}$. 


\section{Appendix D: References}

Atwater, J. and G. Lawrence. 2010. Power potential of a split channel.

REnewable Energy 35: 329-332.

Benson, M. A. and R. W. Carter. 1973. A National Study of the Streamflow DataCollection Program. U.S. Geological Survey. Water-Supply Paper 2028.

Blanchfield, J., C. Garrett, P. Wild and A. Rowe. 2008. The extractable power from a channel linking a bay to the open ocean. Proceedings of the Institution of Mechanical Engineers, Part A: Journal of Power and Energy 222(3): 289-297.

Bryden, I. and S. J. Couch. 2006. ME1 -- marine energy extraction: tidal resource analysis. Renewable Energy 31(2): 133-139.

Couch, S. J. and I. G. Bryden. 2004. The impact of energy extraction on tidal flow development. 3rd IMarEST International Conference on Marine Renewable Energy 2004.

Defne, Z., K. A. Haas and H. M. Fritz. 2011. GIS based multi-criteria assessment of tidal stream power potential: A case study for Georgia, USA. Renewable and Sustainable Energy Reviews 15(5): 2310-2321.

EPRI (Electric Power Research Institute). 2006. Methodology for Estimating Tidal Current Energy Resources and Power Production by Tidal In-Stream Energy Conversion (TISEC) Devices. Palo Alto, CA. EPRI-TP-001-NA (Revision 3). September 29, 2006.

EPRI (Electric Power Research Institute). 2008. System Level Design, Performance, Cost and Economic Assessment--Alaska River In-Stream Power Plants. Palo Alto, CA. EPRI-RP-006-Alaska. October 31, 2008.

Garrett, C. and P. Cummins. 2005. The power potential of tidal currents in channels. Proceedings of the Royal Society. A. 461: 2563-2572.

Garrett, C. and P. Cummins. 2007. The efficiency of a turbine in a tidal channel. Journal of Fluid Mechanics 588: 243-251.

Garrett, C. and P. Cummins. 2008. Limits to tidal current power. Renewable Energy 33(11): 2485-2490. 
Karsten, R. H., J. M. McMillan, M. J. Lickley and R. D. Haynes. 2008. Assessment of tidal current energy in the Minas Passage, Bay of Fundy. Proceedings of the Institution of Mechanical Engineers, Part A: Journal of Power and Energy 222(5): 493-507.

Kartezhnikova, M. and T. M. Ravens. in review. Hydraulic impacts of hydrokinetic devices. Journal of Hydraulic Engineering.

Lunden, L. S. and A. S. Bahaj. 2007. Tidal energy resource assessment for tidal stream generators. Journal of Power and Energy 221(2): 137-146.

McKay, L., T. R. Bondelid, A. Rea, C. Johnston, R. Moore and T. Dewald. 2012. NHDPlus Verson 2: User Guide. Prepared for U.S. Environmental Protection Agency, Office of Water. August 10, 2012.

Miller, G., J. Franceschi, W. Lese and J. Rico. 1986. The Allocation of Kinetic Hydro Energy Conversion SYSTEMS(KHECS) in USA Drainage Basins: Regional Resource and Potential Power. NYUDAS 86-151. August 1986.

Munson, B. R., D. F. Young and T. H. Okiishi. 2002. Fundamentals of fluid mechanics. Wiley, New York.

NRC-CHC (National Research Council of Canada - Canadian Hydraulic Centre). 2010. Assessment of Canada's Hydrokinetic Power Potential: Phase I Report. Methodology and Data Review.

Ortgega-Achury, S. L., W. H. McAnally, T. E. Davis and J. L. Martin. 2010. Hydrokinetic Power Review. Prepared for U.S. Army Corps of Engineers Research and Development Center, Vicksburg, Mississippi.

Polagye, B., P. C. Malte, M. Kawase and D. Durran. 2008. Effect of large-scale kinetic power extraction on time-dependent estuaries. Journal of Power and Energy 222(5): 471-484.

Polagye, B. 2009. Hydrodynamic Effects of Kinetic Power Extraction by In-Stream Tidal Turbines. Doctoral dissertation. University of Washington, Seattle, WA.

Ravens, T. M., M. Johnson and M. Kartezhnikova. in preparation. Comparison of methods for estimating hydraulic impacts of hydrokinetic devices.

Shapiro, G. 2010. Effect of tidal stream power generation on the region-wide circulation in a shallow sea. Ocean Science Discussions 7: 1785-1810.

Sun, X., J. P. Chick and I. Bryden. 2008. Laboratory-Scale Simulation of Energy Extraction from Tidal Currents. Renewable Energy 33(6): 1267-1274.

Sutherland, G., M. Foreman and C. Garrett. 2007. Tidal current energy assessment for Johnstone Strait, Vancouver Island. Journal of Power and Energy $221(2)$. 
Walkington, I. and R. Burrows. 2009. Modelling tidal stream power potential. Applied Ocean Research 31: 239-245.

Yang, Z. and T. Wang. 2011. Assessment of Energy Removal Impacts on Physical Systems: Development of MHK Module and Analysis of Effects on Hydrodynamics. U.S. Department of Energy, Pacific Northwest National Laboratory. September 2011. 


The Electric Power Research Institute, Inc. (EPRI, www.epri.com) conducts research and development relating to the generation, delivery and use of electricity for the benefit of the public. An independent, nonprofit organization, EPRI brings together its scientists and engineers as well as experts from academia and industry to help address challenges in electricity, including reliability, efficiency, health, safety and the environment. EPRI also provides technology, policy and economic analyses to drive long-range research and development planning, and supports research in emerging technologies. EPRI's members represent approximately 90 percent of the electricity generated and delivered in the United States, and international participation extends to more than 30 countries. EPRI's principal offices and laboratories are located in Palo Alto, Calif.; Charlotte, N.C.; Knoxville, Tenn.; and Lenox, Mass.

Together...Shaping the Future of Electricity

\section{Program:}

Environment

(C) 2012 Electric Power Research Institute (EPRII), Inc. All rights reserved. Electric Power Research Institute, EPRI, and TOGETHER...SHAPING THE FUTURE OF ELECTRICITY are registered service marks of the Electric Power Research Institute, Inc.

1026880 